\title{
Growth, Slowdowns, and Recoveries
}

\author{
Francesco Howard Kung \\ Bianchi \\ $\begin{array}{cc}\text { Duke University/ } & \text { London Business } \\ \text { Cornell University/ } & \text { School }\end{array}$ \\ NBER/ CEPR
}

November 2014

ERID Working Paper Number 184

This paper can be downloaded without charge from the Social Science Research Network Electronic Paper Collection:

http://ssrn.com/abstract=2577505

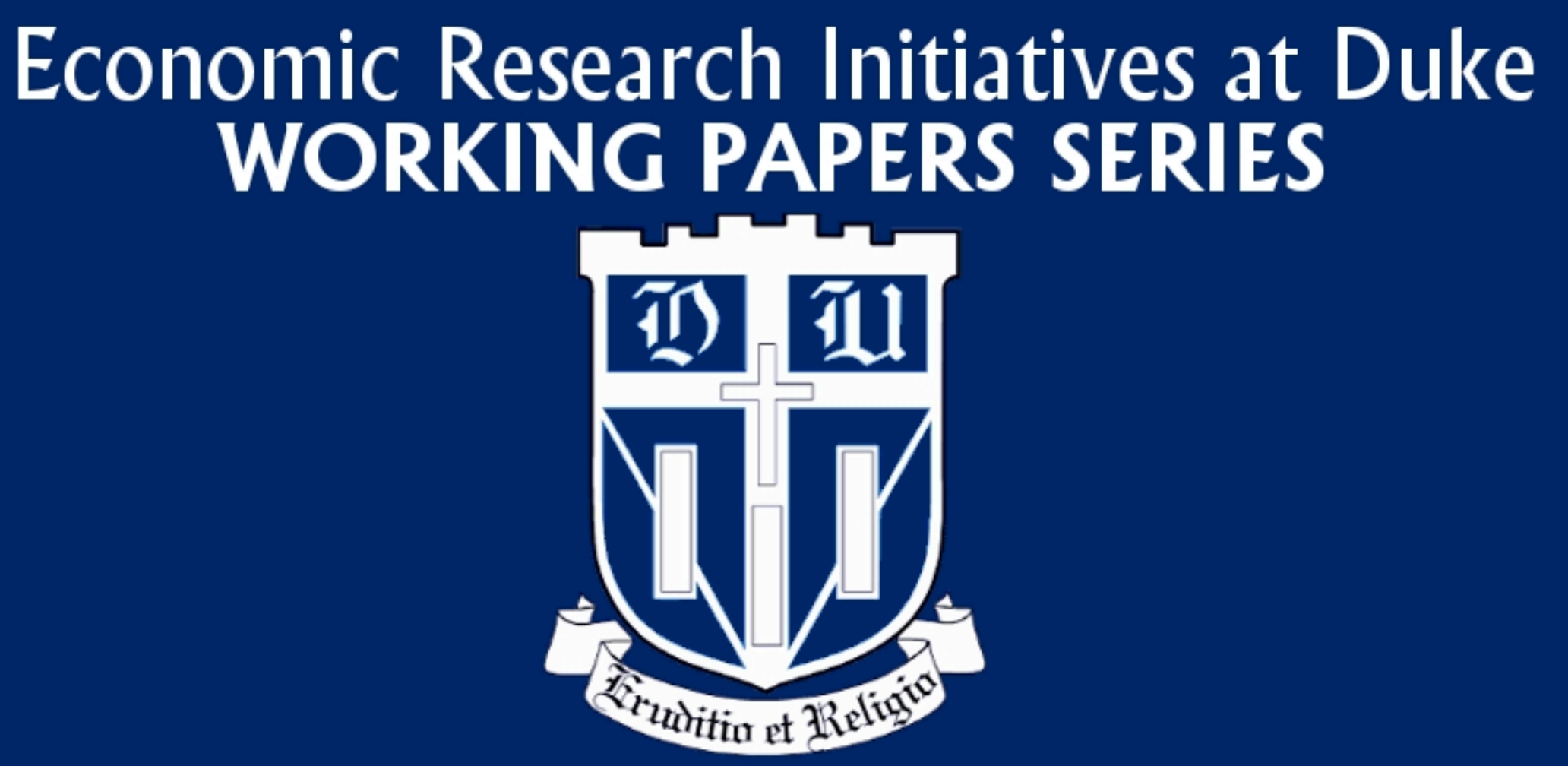




\title{
Growth, Slowdowns, and Recoveries
}

\author{
Francesco Bianchi* Howard Kung ${ }^{\dagger}$
}

November 2014 ‡

\begin{abstract}
We construct and estimate a model that features endogenous growth and technology diffusion. The spillover effects from research and development provide a link between business cycle fluctuations and long-term growth. Therefore, productivity growth is related to the state of the economy. Shocks to the marginal efficiency of investment explain the bulk of the low-frequency variation in growth rates. Transitory inflationary shocks lead to persistent declines in economic growth. During the Great Recession, technology diffusion dropped sharply, while long-term growth was not significantly affected. The opposite occurred during the 2001 recession. The growth mechanism induces positive comovement between consumption and investment.
\end{abstract}

Keywords: DSGE model, Endogenous growth, Technology Diffusion, Business cycles, Bayesian Methods.

\footnotetext{
*Cornell, Duke, NBER, and CEPR. francesco.bianchi@cornell.edu

${ }^{\dagger}$ London Business School. hkung@london.edu

${ }^{\ddagger}$ We thank Ufuk Akcigit, Ravi Bansal, Julieta Caunedo, Roger Farmer, Francisco Gomes, Leonardo Melosi, Karel Mertens, Pietro Peretto, Assaf Razin, and seminar participants at the Society of Economic Dynamics Meeting, Duke University, University of British Columbia, London Business School, and Cornell University for comments. We also thank Alexandre Corhay, Gonzalo Morales, and Yang Yu for research assistance.
} 


\section{Introduction}

Macroeconomic growth rates exhibit low-frequency patterns often associated with innovation and technological change. The advent of electricity and the introduction of computers are each associated with persistent waves in the trend component of productivity. ${ }^{1}$ The diffusion rate of new technologies is also important for explaining productivity dynamics and for reconciling crosscountry differences in economic growth. ${ }^{2}$ Despite these efforts in the growth literature, there is no consensus on the macroeconomic sources of prolonged productivity slowdowns and the subsequent recoveries. In particular, there is substantial disagreement in projecting the long-run effects of the Great Recession of 2008-2009 on economic growth. ${ }^{3}$

In this paper, we quantitatively examine the driving forces of economic growth at both mediumand long-term frequencies by building and estimating a Dynamic Stochastic General Equilibrium (DSGE) model that incorporates endogenous technological progress and diffusion rates. We then use our estimated model to enhance our understanding of two key events in US economic history, the Great Recession and the Great Inflation. The model embeds an endogenous growth framework of vertical innovations (Aghion and Howitt (1992), Grossman and Helpman (1991), and Peretto (1999)) and technology adoption (Parente and Prescott (1994)) in a medium-size DSGE framework (Christiano, Eichenbaum, and Evans (2005), Smets and Wouters (2007), and Justiniano and Primiceri (2008)) that features a rich set of macroeconomic shocks. The spillover effects from knowledge accumulation and variation in technology diffusion rates provide two important transmission channels for business cycle shocks to long-term growth. In equilibrium, total factor productivity (TFP) growth is endogenous and related to research and development (R\&D) and technology diffusion rates. Thus, this framework allows us to analyze the impact of business cycle disturbances, including demand, monetary policy, and investment shocks, on TFP and trend growth.

Our model produces a link between TFP and the state of the economy. In the estimated model, technology diffusion rates explain most of the variability in TFP growth, while R\&D rates are related to long-run trends in TFP growth. The return on adopting existing technology varies significantly in response to changes in market conditions. Due to high R\&D adjustment costs, transitory disturbances are mostly absorbed by diffusion rates. In other words, the optimal response to variations in the marginal return of technology mostly consists of adjusting technology adoption

\footnotetext{
${ }^{1}$ See, for example, Jovanovic and Rousseau (2005) and Gordon (2010) for surveys.

${ }^{2}$ Prominent examples include Barro (1991), Parente and Prescott (1994), Barro and Sala-i-Martin (1997), Basu and Weil (1998), Comin and Hobijn (2004), and Comin and Hobijn (2010b)

${ }^{3}$ Gordon (2014) and Fernald (2014) are examples that provide opposing views.
} 
rates, as opposed to changing $R \& D$ expenditures. We find this result appealing as the accumulation of knowledge through $R \& D$ is a process that requires expending a steady amount of resources, while the decision of how much technology to incorporate in the production process of goods can be more easily adjusted in response to market conditions.

Our estimates suggest that the majority of the medium- and low-frequency variation in growth rates, such as output, consumption, and investment, is attributed to shocks to the marginal efficiency of physical investment (MEI shocks). At the same time, shocks to the marginal efficiency of investment also explain the bulk of the variation at business cycle frequencies of investment growth, consistent with evidence from Justiniano, Primiceri, and Tambalotti (2010) and Justiniano, Primiceri, and Tambalotti (2011). Therefore, our estimation results suggest a tight link between business cycle fluctuations and long-term growth dynamics. For instance, in our endogenous growth model around $70 \%$ of the variation in output growth at frequencies between 8 and 50 years is due to MEI shocks, while stationary technology shocks only explain around $20 \%$. Also, over $60 \%$ of the low-frequency fluctuations in consumption growth is due to MEI shocks, while half of the business cycle variation in consumption growth is due to preference shocks. In the model, a positive shock to the marginal efficiency of investment increases investment in physical capital, which raises the marginal productivity of $\mathrm{R} \& \mathrm{D}$ capital (i.e., knowledge capital) due to complementarities in production. Greater accumulation of $R \& D$ capital and higher technology diffusion rates lead to a persistent increase in growth due to knowledge spillovers.

Accounting for these two margins of technology adjustment, R\&D and diffusion rates, has important implications for the consequences of a recession, especially over longer horizons. We find that the Great Recession was associated with a large drop in technology diffusion rates, while R\&D was not significantly affected. In contrast, during the 2001 recession there was a significant decline in R\&D investment after the bust of the information technology (IT) bubble, but only a modest change in the diffusion rate of existing technology. Consequently, while the current recession has been substantially more severe in the short-term, our model suggests that trend growth was less affected during the Great Recession compared to the 2001 recession, which accords with the empirical evidence from Fernald (2014). While the current model projections suggest that long-run growth prospects have remained stable during the current recession, our results also imply that if market conditions did not improve, $\mathrm{R} \& \mathrm{D}$ would eventually start declining.

Further, counterfactual experiments suggest that during the Great Recession, accommodative monetary and fiscal policies helped to stabilize both R\&D rates and the diffusion of existing tech- 
nology, which has important consequences on the trend component of productivity. In a model with exogenous growth, TFP and trend growth do not depend on policymakers' actions. As a result, these models generally imply a steady and relatively fast return to the trend, independent from the actions undertaken by the fiscal and monetary authorities. Instead, in the present model sustaining demand during a severe recession can deeply affect the medium- and long-term outcomes for the economy. This result has important implications for the role of policy intervention during recessions. For example, we believe that the link between policy interventions and growth is important in light of the recent debate on the consequences of performing fiscal consolidations during recessions (Alesina and Ardagna (2010) and Guajardo, Leigh, and Pescatori (2014) provide opposing views).

The differences between the two recessions detected by our estimates are in line with a heuristic interpretation of the two events. The recent recession originated, or at least coincided, with a severe financial crisis. Shocks to the marginal efficiency of investment can be regarded as a reduced-form way to capture the ease to which firms can access external financing. For example, Justiniano, Primiceri, and Tambalotti (2011) argue that this shock is highly correlated with the credit spread between the returns on high-yield and AAA corporate bonds. On the contrary, the 2001 recession coincided with the end of the IT bubble, an event that affected a sector with high R\&D intensity. Our model captures this fact with a shock to the marginal efficiency of R\&D, which is the analogue of the MEI shock for knowledge capital.

The model has also interesting implications for the interpretation of the Great Inflation of the 1970s. Short-lived inflationary technology shocks have persistent negative effects on economic growth, primarily through the technology diffusion channel. In the estimated model, the oil shock episodes of the 1970s contributed to a decline in technology diffusion, which led to an extended slump in productivity growth. In the model, a fall in productivity increases real marginal costs, which implies an increase in inflation. At the same time, the negative productivity shock reduces the marginal productivity of $R \& D$ capital. As there are high costs for adjusting $R \& D$, technology diffusion rates fall aggressively while R\&D only declines slightly, albeit more persistently. In sum, TFP growth drops sharply and persistently, while the increase in inflation is relatively short-lived.

The endogenous growth mechanism generates positive responses in consumption and investment to investment shocks, which is sometimes a challenge in DSGE models (e.g., Barro and King (1984) and Justiniano, Primiceri, and Tambalotti (2010)). In standard DSGE models, positive investment shocks often lead to a decline (or an initial decline) in consumption, while investment, hours and 
output increase. In our model, the investment shocks are amplified as they affect TFP growth through the endogenous growth and diffusion channels. Thus, a positive investment shock increases output more than in the standard models without the endogenous growth and diffusion channels, which helps to generate a positive consumption response. Finally, monetary policy shocks induce positive comovement between measured productivity and inflation, consistent with evidence from Evans and dos Santos (2002).

This paper makes two methodological contributions with respect to the existing literature. We introduce a Schumpeterian growth framework in a medium-size DSGE model with nominal rigidities, captured by Calvo pricing. ${ }^{4}$ Second, we structurally estimate the model using Bayesian methods. To the best of our knowledge, this is the first paper that estimates a quantitative model of the business cycle augmented with endogenous growth and technology diffusion margins. In this respect, our work builds on, but differs from the seminal contribution of Comin and Gertler (2006) across several dimensions. First, we allow for nominal rigidities and a role for monetary policy, while they use a real model that abstracts from the effects of inflation and monetary policy. Second, they use an endogenous growth framework with horizontal innovations (i.e., expanding variety model of Romer (1990)) whereas we use a growth model with vertical innovations. Third, we perform structural estimation without detrending the data, while they rely on calibration and pre-filtering the data. Finally, we make use of the recently released series for quarterly R\&D investment to inform us on the process of knowledge accumulation.

Our approach of estimating a structural model helps to elucidate the link between R\&D, growth, and business cycle dynamics. Due to data limitations, measuring the sources of low-frequency growth fluctuations at long horizons is inherently difficult. For example, it would be hard to learn about the impact of R\&D by only looking at its effect on growth decades later. Instead, our endogenous growth framework imposes joint economic restrictions on the evolution of macroeconomic quantities at short- and long-horizons. Therefore, conditional on the model, the dynamics at business cycle frequencies are also informative about the low-frequency behavior of the economy. This is because, given a parametric specification, the deep parameters that govern high- and low-frequency movements are invariant and can be inferred by examining fluctuations at all frequencies.

This paper is related to the literature linking business cycles to growth. ${ }^{5}$ Barlevy (2004) shows that the welfare costs of business cycle fluctuations are higher in an endogenous growth framework

\footnotetext{
${ }^{4}$ For a survey on Schumpeterian growth models, see Aghion, Akcigit, and Howitt (2013).

${ }^{5}$ Also, see Comin (2009) for a general survey of this approach.
} 
due to the adverse effects of uncertainty on trend growth. Aguiar and Gopinath (2007) find that shocks to trend growth are the primary source of fluctuations in emerging markets. Comin and Gertler (2006) show that a stochastic version of an expanding variety endogenous growth model generates medium-term cycles that are driven by the dynamics of R\&D. Kung and Schmid (2014) examine the asset pricing implications of a stochastic endogenous growth model and relate the R\&D-driven low-frequency cycles in growth to long-run risks. Kung (2014) builds a New Keynesian model of endogenous growth and shows how the model can rationalize key term structure facts. In the context of the asset pricing literature on long-run risks based on the work by Bansal and Yaron (2004), our results imply that MEI shocks, typically associated with business cycle fluctuations, are an important source of long-run risks. Guerron-Quintana and Jinnai (2013) use a stochastic endogenous growth model to analyze the effect of liquidity shocks to trend growth. Our paper distinguishes itself as it represents, to the best of our knowledge, the first attempt to estimate a state of the art medium-size DSGE model with endogenous growth. Further, our estimation framework allows us to more precisely identify the macroeconomic sources of low-frequency growth fluctuations.

Our paper also relates to models that feature technology diffusion. For example, Parente and Prescott (1994), Basu and Weil (1998), and Comin and Hobijn (2010a) illustrate that variation in technology adoption rates can help explain the observed cross-country differences in TFP and output growth. Comin and Gertler (2006) and Comin, Gertler, and Santacreu (2009) illustrate that endogenous diffusion rates provide a strong propagation channel at medium-term frequencies. Our model complements these contributions by showing that medium-term fluctuations in technology diffusion rates are mostly driven by shocks to the marginal efficiency of investment. Further, we show that accounting for the technology diffusion channel is important for explaining the dynamics of TFP during major economic events, such as the Great Recession and Great inflation. The connection between market conditions, demand shocks, and measured TFP relates to Bai, RiosRull, and Storesletten (2012) who build a model where a search friction prevents perfect matching between potential customers and producers. As a result larger demand induces more search, which in turn, increases output in the economy. Finally, our paper is connected to McGrattan and Prescott (2010) who study the role of intangible investment for explaining the economic boom of the 1990s.

We also relate to papers examining the causes and long-term impact of the Great Recession. Eggertsson and Mehrotra (2014) illustrate how a debt deleveraging shock can induce a persistent, or even permanent, economic slowdown in a New Keynesian model with overlapping generations. 
Christiano, Eichenbaum, and Trabandt (2014) show how interactions of financial frictions with a zero lower bound constraint on nominal interest rates in a DSGE framework can help explain the dynamics of macroeconomic aggregates during the Great Recession. Bianchi and Melosi (2014) link the outcomes of the current recession to policy uncertainty. Our paper focuses on the effects of the Great Recession through the R\&D and technology diffusion margins, and thus, we view our contribution as complementary to the existing literature.

The paper is organized as follows. Section 2 illustrates the model. Section 3 presents the estimates. Section 4 studies the Great Recession and the Great Inflation in light of our model. Section 5 concludes.

\section{Model}

The benchmark model is a medium-scale DSGE model with endogenous growth and technology diffusion. The endogenous growth production setting with vertical innovations follows Kung (2014) and the additional frictions and shocks are standard in the literature and taken from Christiano, Eichenbaum, and Evans (2005) and Bianchi (2013).

\subsection{Representative Household}

The representative household has preferences over consumption $C_{t}$ and leisure $L_{t}$ with external habits:

$$
E_{t} \sum_{s=0}^{\infty} \beta^{s} \zeta_{C, t+s}\left\{\log \left(C_{t+s}-\Phi_{c} \bar{C}_{t+s-1}\right)-\chi \frac{L_{t+s}^{1+\sigma_{L}}}{1+\sigma_{L}}\right\}
$$

where $\beta$ is the discount rate, $\Phi_{c}$ is an external habit parameter, $C_{t}$ denotes consumption, $\bar{C}_{t}$ is average consumption, $L_{t}$ denotes the labor service supplied by the household, and $\sigma_{L}$ is the inverse of the the Frisch labor supply elasticity. The variable $\zeta_{C, t}$ represents an intertemporal preference shock with mean one and time series representation:

$$
\log \left(\zeta_{C, t}\right)=\rho_{\zeta_{C}} \log \left(\zeta_{C, t-1}\right)+\sigma_{\zeta_{C}} \epsilon_{\zeta_{C}, t}
$$

where $\epsilon_{\zeta_{C}, t} \sim N(0,1)$.

Households own the physical and R\&D capital (i.e., knowledge) stocks, ${ }^{6} \bar{K}_{t}$ and $\bar{N}_{t}$, respectively

\footnotetext{
${ }^{6}$ We assume the household accumulates both physical and knowledge capital to stay as close as possible to standard medium-size DSGE models, such as Christiano, Eichenbaum, and Evans (2005). The dynamics of the model are quantitatively similar if instead firms accumulated the capital stocks (see, for example, Kung (2014)).
} 
and rent out capital services, $K_{t}$ and $N_{t}$ to a competitive capital market at the rate $P_{t} r_{t}^{k}$ and $P_{t} r_{t}^{n}$, by selecting the capital utilization rates $u_{t}^{k}$ and $u_{t}^{n}: K_{t}=u_{t}^{k} \bar{K}_{t-1}$ and $N_{t}=u_{t}^{n} \bar{N}_{t-1}$. Increased utilization requires increased maintenance costs in terms of investment goods per unit of physical or $\mathrm{R} \& \mathrm{D}$ capital measured by the function $a_{i}\left(u_{t}^{i}\right)$, for $i=k, n$. In the linearized solution of the model, only the ratio $a_{i}^{\prime \prime}\left(u^{i}\right) / a_{i}^{\prime}\left(u^{i}\right)=\sigma_{i}$ is relevant for the law of motion of the economy, where $u^{i}$ is the steady-state value for $u_{t}^{i}$. We interpret the variable $u_{t}^{n}$ as the technology diffusion rate of existing technology in similar spirit as Parente and Prescott (1994) and Comin and Hobijn (2010a). Thus, we interpret $\bar{N}_{t}$ as the stock of knowledge generated by R\&D while $N_{t}$ is the adopted stock of knowledge that is directly available for use in production and that depends on the diffusion rate $u_{t}^{n}$. In line with this interpretation, maintenance costs for the utilization of $\mathrm{R} \& \mathrm{D}$ include the costs associated with integrating new technologies and scrapping old technologies in the production process.

The household accumulates physical capital subject to the following law of motion:

$$
\bar{K}_{t}=\left(1-\delta_{k}\right) \bar{K}_{t-1}+\zeta_{I, t}\left[1-\Psi_{k}\left(\frac{I_{t}}{I_{t-1}}\right)\right] I_{t}
$$

The function $\Psi_{k}$ is convex and in the steady-state $\Psi_{k}=0=\Psi_{k}^{\prime}$. The variable $\zeta_{I, t}$ represents a mean one shock to the marginal efficiency of investment and evolves as:

$$
\log \left(\zeta_{I, t}\right)=\rho_{\zeta_{I}} \log \left(\zeta_{I, t-1}\right)+\sigma_{\zeta_{I}} \epsilon_{\zeta_{I}, t}
$$

where $\epsilon_{\zeta_{I}, t} \sim N(0,1)$.

The household accumulates knowledge capital subject to the following law of motion:

$$
\bar{N}_{t}=\left(1-\delta_{n}\right) \bar{N}_{t-1}+\zeta_{S, t}\left[1-\Psi_{n}\left(\frac{S_{t}}{S_{t-1}}\right)\right] S_{t}
$$

where function $\Psi_{n}$ is convex and in the steady-state $\Psi_{n}=0=\Psi_{n}^{\prime}$. The variable $\zeta_{S, t}$ represents a mean one shock to the marginal efficiency of R\&D investment and evolves as:

$$
\log \left(\zeta_{S, t}\right)=\rho_{\zeta_{S}} \log \left(\zeta_{S, t-1}\right)+\sigma_{\zeta_{S}} \epsilon_{\zeta_{S}, t}
$$

where $\epsilon_{\zeta_{S}, t} \sim N(0,1)$. The shock $\zeta_{S, t}$ can be interpreted as capturing variations in the efficiency with which R\&D investment can transformed into new knowledge (e.g., blueprint ideas). Such 
variations are likely to depend on disturbances that are specific to sectors that are characterized by high $R \& D$ intensity.

The household budget constraint is:

$P_{t} C_{t}+P_{t} \zeta_{\Upsilon, t}^{-1} I_{t}+P_{t} S_{t}+B_{t}=B_{t-1} R_{t-1}+P_{t} \bar{K}_{t-1}\left[r_{t}^{k} u_{t}^{k}-a_{k}\left(u_{t}^{k}\right)\right]+P_{t} \bar{N}_{t-1}\left[r_{t}^{n} u_{t}^{n}-a_{n}\left(u_{t}^{n}\right)\right]+W_{t} L_{t}-T_{t} P_{t}$,

where $\zeta_{\Upsilon, t}^{-1}$ captures the cost, in terms of consumption goods, of one unit of investment. Since the currency price of the consumption good is $P_{t}$, the currency price of a unit of investment good is $P_{t} \zeta_{\Upsilon, t}^{-1}$. The law of motion for $\zeta_{\Upsilon, t}^{-1}$ is given by:

$$
\log (\zeta \Upsilon, t)=\rho_{\zeta \Upsilon} \log \left(\Upsilon_{\Upsilon, t-1}\right)+\sigma_{\zeta \Upsilon} \epsilon_{\zeta \Upsilon, t}
$$

We allow for changes in the relative price of physical investment to capture technological progress that affects the rate of transformation between consumption and investment, but that is not directly linked to the accumulation of knowledge through R\&D investment. Variation in relative price of investment is needed mostly to correctly capture the process of physical capital accumulation that occurred in the US starting from World War II. Furthermore, these relative price shocks allow us to interpret the shocks to the marginal efficiency of physical investment in a way that is in line with the literature (e.g., Justiniano, Primiceri, and Tambalotti (2011) and Christiano, Eichenbaum, and Trabandt (2014)).

\section{$2.2 \quad$ Firms}

A representative firm produces the final consumption goods in a perfectly competitive market. The firm uses a continuum of differentiated intermediate goods $Y_{j, t}$ as input in the CES production technology

$$
Y_{t}=\left(\int_{0}^{1} Y_{j, t}^{1 / \lambda_{f}} d j\right)^{\lambda_{f}}
$$

where $\lambda_{f}$ is the markup over marginal cost for intermediate goods firms. The profit maximization problem of the firm yields the following isoelastic demand schedule

$$
Y_{j, t}=Y_{t}\left(\frac{P_{j, t}}{P_{t}}\right)^{-\lambda_{f} /\left(\lambda_{f}-1\right)}
$$


where $P_{t}$ is the nominal price of the final goods and $P_{j, t}$ is the nominal price of intermediate good $i$. The price of final goods is obtained by integrating over the intermediate goods prices.

The intermediate good $j$ is produced by a price-setting monopolist using the following production function:

$$
Y_{j, t}=\max \left\{K_{j, t}^{\alpha}\left(A_{t} N_{j, t}^{\eta} N_{t}^{1-\eta} L_{j, t}\right)^{1-\alpha}-F \cdot \bar{N}_{t}, 0\right\}
$$

where $N_{t} \equiv \int_{0}^{1} N_{j} d j$ is the aggregate stock of $\mathrm{R} \& \mathrm{D}$ capital and $(1-\eta) \in[0,1]$ represents the degree of technological spillovers. In addition, the inputs $K_{j, t}$ and $N_{j, t}$ are accumulated using the final goods. The variable $A_{t}$ represents a stationary aggregate productivity shock that is common across firms and evolves in logs as an $\mathrm{AR}(1)$ process:

$$
a_{t}=\left(1-\rho_{a}\right) a^{\star}+\rho_{a} a_{t-1}+\sigma_{a} \epsilon_{a, t}
$$

where $a_{t} \equiv \log \left(A_{t}\right)$ and $\epsilon_{a, t} \sim N(0,1)$ is an i.i.d. shock. The scale parameter $a^{\star}$ is used to match balanced growth evidence and we discuss its role below.

Following Calvo (1983), a randomly chosen fraction $1-\zeta_{p}$ of the intermediate goods firms are permitted to reoptimize their price every period. Of the remaining firms, a randomly selected fraction $1-\iota_{p}$ must set $P_{i, t}=\Pi P_{i, t-1}$ and a fraction $\iota_{p}$ sets $P_{i, t}=\Pi_{t-1} P_{i, t-1}$, where $\Pi_{t}=P_{t} / P_{t-1}$ is gross inflation.

\subsection{Market Clearing and Fiscal Authority}

The market clearing condition for this economy is $C_{t}+\zeta_{\Upsilon, t}^{-1} I_{t}+S_{t}+G_{t}=Y_{t}^{G}$, where $G_{t}$ denotes government expenditures and $Y_{t}^{G}$ is measured GDP (i.e., $\left.Y_{t}^{G}=Y_{t}-a_{k}\left(u_{t}^{k}\right) \bar{K}_{t-1}-a_{n}\left(u_{t}^{n}\right) \bar{N}_{t-1}\right)$. The government issues short-term bonds and moves lump-sum taxes $T_{t}$ in order to finance government expenditure. Government expenditure follows an exogenous law of motion:

$$
\hat{g}_{t}=\rho_{g} \hat{g}_{t-1}+\sigma_{g} \epsilon_{g, t}
$$

where $\epsilon_{g, t} \sim N(0,1), \hat{g}_{t}=\ln \left(g_{t} / g\right)$, and $g_{t} \equiv G_{t} / \bar{N}_{t}$. In the steady-state, $G / Y^{G}=\eta_{G}$. 


\subsection{Monetary Policy}

The central bank sets the nominal interest rate according to a feedback rule:

$$
\frac{R_{t}}{R}=\left(\frac{R_{t-1}}{R}\right)^{\rho_{R}}\left[\left(\frac{\Pi_{t}}{\Pi_{t}^{*}}\right)^{\phi_{\pi}}\left(\frac{\Delta Y_{t}}{\Delta Y}\right)^{4 \phi_{d y}}\right]^{1-\rho_{R}} e^{\sigma_{R} \epsilon_{R, t}}
$$

where $R, \Pi$, and $\Delta Y$ are the steady-state values of the nominal interest rate, inflation, and output growth respectively. The central bank responds to deviations in inflation and annualized output growth from their respective target levels, adjusting for the monetary policy rate. Unanticipated deviations from the interest rate rule are captured by $\epsilon_{R, t}$.

The target for inflation $\Pi_{t}^{*}$ is assumed to follow an autoregressive process:

$$
\pi_{t}^{*}=\left(1-\rho_{\pi}\right) \pi^{*}+\rho_{\pi} \pi_{t-1}^{*}+\sigma_{\pi} \epsilon_{\pi, t}
$$

where $\pi_{t}^{*}=\log \left(\Pi_{t}^{*}\right)$ and $\pi^{*}=\log \left(\Pi^{*}\right)$ is the steady state inflation target. We allow for changes in the target to accommodate the possibility that the inflationary stance of the Federal Reserve has changed over time. An alternative approach would consist of explicitly modeling changes in monetary policy as in Bianchi (2013). While we regard this as an interesting path for future research, at this stage it would add an unnecessary layer of complexity.

\subsection{Solving the Model}

The trend component in TFP, $\bar{N}_{t}$, is endogenous. In order to induce stationarity, aggregate variables, such as, consumption, R\&D, investment, output and government expenditures, are detrended by $\bar{N}_{t}$. Once the model is rewritten in terms of stationary variables, the nonstochastic steady state can be computed, which includes the endogenous trend growth rate $\Delta \bar{N}$. In particular, the trend growth rate is a function of the deep parameters of the model:

$$
\Delta \bar{N}=\beta\left(\frac{\alpha}{\lambda_{f}} \bar{k}^{1-\alpha} e^{a^{\star}(1-\alpha)}+1-\delta_{k}\right)
$$

where $\bar{k}$ is defined implicitly by the no-arbitrage equation equating the return on physical capital to the return on knowledge capital, ${ }^{7}$ and therefore a function of the model parameters.

\footnotetext{
${ }^{7}$ The no-arbitrage equation in the deterministic steady state is given by: $\frac{\alpha}{\lambda_{f} \Pi} \cdot \bar{k}^{\alpha-1}(A L)^{1-\alpha}+\left(1-\delta_{k}\right)=\frac{\eta(1-\alpha)}{\lambda_{f} \Pi}$. $\bar{k}^{\alpha}(A L)^{1-\alpha}+\left(1-\delta_{n}\right)$
} 
Note that the growth rate depends on the unconditional mean of the stationary technology shock $a^{\star}$, which is a scale parameter used to match balanced growth evidence following Comin and Gertler (2006) and Kung and Schmid (2014). After obtaining the non-stochastic steady state values, we log-linearly approximate the equations around the steady state values (the linearized equations are in the appendix).

\subsection{TFP Growth}

Imposing the symmetric equilibrium conditions, the aggregate variable output $\tilde{Y}_{t}$ can be expressed as:

$$
\tilde{Y}_{t}=\left(Z_{t} L_{t}\right)^{1-\alpha} K_{t}^{\alpha}
$$

where measured TFP, $Z_{t}$ is endogenous and depends on the diffusion rate of technology and the stock of knowledge:

$$
Z_{t}=A_{t} u_{t}^{n} \bar{N}_{t-1}
$$

As in Comin and Gertler (2006) and Kung and Schmid (2014), the trend component in TFP, $\bar{N}_{t-1}$, is endogenous and time-varying. For the discussion of the results below, we define $a_{t} \equiv \log \left(A_{t}\right)$ as the stationary shock to TFP, $u_{t}^{n}$ is the technology diffusion rate, $\bar{N}_{t-1}$ is the stock of knowledge, and $N_{t} \equiv u_{t}^{n} \bar{N}_{t-1}$ is the stock of adopted knowledge.

\section{Estimates}

This section presents the main estimation results. We estimate the model using a Metropolis Hastings algorithm. As observables, we use seven series of U.S. quarterly data: real GDP per capita, annualized quarterly inflation, the federal funds rate (FFR), real consumption per capita, investment in physical capital in terms of consumption units, investment in R\&D capital in terms of consumption units, and the relative price of investment. All variables except for inflation and the FFR enter as log differences and are downloaded by the BEA website. The sample spans 1954:Q3 to 2013:Q3. To the best of our knowledge, this is the first paper that makes use of the newly released series for quarterly $R \& D$ in a structural estimation. 


\subsection{Parameter Estimates}

Table 1 reports priors, modes, means, and 90\% error bands for the DSGE parameters. The priors are diffuse and in line with the literature. For the parameters that characterize the endogenous growth mechanism, we choose diffuse priors and take an agnostic view on their likely values, given that there is no previous evidence to guide us. We also specify a prior on the steady state trend growth rate: $100 \Delta \bar{N} \sim N(.45, .05)$. Given that steady state growth in the model is a function of several model parameters, this choice translates in a joint prior on these model parameters.

The posterior parameter estimates suggest a significant degree of price stickiness and habit formation consistent with the literature (e.g., Altig, Christiano, Eichenbaum, and Linde (2011), Del Negro, Schorfheide, Smets, and Wouters (2007), Justiniano, Primiceri, and Tambalotti (2010)). We find very high adjustment costs for $\mathrm{R} \& \mathrm{D}, S_{N}^{\prime \prime}$, and a small elasticity of firm-specific R\&D with respect to its output, $\eta$, which both make $\mathrm{R} \& \mathrm{D}$ less responsive to macroeconomic shocks and is important for capturing persistent R\&D dynamics. On the other hand, the low value for $\sigma_{n}$ implies that the technology diffusion rate is very responsive to changes in the return of adopted knowledge. We interpret these two findings as implying that $R \& D$ needs to be carried on consistently over time in order to produce significant results and that the important margin for technology adjustment relies on varying the adoption rate of existing knowledge. Furthermore, the small value for $\eta$ also implies that there are large positive spillover effects from innovation, which is consistent with microeconomic evidence from Griliches (1992). Finally, the depreciation rate for R\&D capital turns out to be substantially lower than the one for physical capital, which again is a reflection of the smooth R\&D dynamics.

\subsection{Variance decomposition}

In this section, we analyze the properties of the estimated model in the frequency domain. Before proceeding, it is worth recalling that the model implied TFP is the product of three different components: The stationary technology shock, the diffusion rate of existing knowledge, and knowledge itself. Namely:

$$
T F P_{t}=\underset{\text { Stat. tech. shock }}{A_{t}} * \underset{\text { Diffusion }}{u_{t}^{n}} * \bar{N}_{t-1}
$$

Furthermore, we label the product of diffusion and knowledge adopted knowledge: $N_{t}=u_{t}^{n} \bar{N}_{t-1}$. We find useful to define adopted knowledge because, as we will see, this component captures the bulk of the fluctuations in the model implied TFP, while the long term component is fairly stable. 
These definitions imply that TFP growth and adopted knowledge growth can be expressed as:

$$
\begin{aligned}
& \Delta t f p_{t}=\underset{\Delta \text { Stat. tech. shock }}{\Delta a_{t}}+\underset{\Delta \text { Adopted knowledge }}{\Delta n_{t}} \\
& \Delta n_{t}=\underset{\Delta \text { Diffusion }}{\Delta u_{t}^{n}}+\underset{\Delta \text { Knowledge }}{\Delta \bar{n}_{t-1}}
\end{aligned}
$$

where we have used lower case letters to denote the logs of the corresponding economic variables.

Table 2 decomposes the model implied variance of the observed variables and the components of the model implied TFP across three frequency intervals. Long term frequencies correspond to cycles of more than 50 years, medium term frequencies are associated with cycles between 8 and 50 years, whereas business cycle frequencies correspond to cycles of duration between 0.5 and 8 years. For all the observed variables the volatility at medium term frequencies plays a significant role, consistent with the findings from Comin and Gertler (2006). In fact, for inflation, the FFR, consumption growth, and R\&D growth more than $50 \%$ of volatility is explained by medium term fluctuations. Furthermore, for investment growth and GDP growth the variance of the medium term and business cycle components are quite similar in magnitude.

For model-implied TFP, the decomposition across frequencies varies depending on its components, adopted knowledge $\left(N_{t}=u_{t}^{n} \bar{N}_{t-1}\right)$ and knowledge $\left(\bar{N}_{t}\right)$. The growth rate of TFP and adopted knowledge exhibit fluctuations mostly at business cycle frequencies, which reflects the large estimated value of the elasticity of technology diffusion with respect to its return. On the other hand, the fluctuations of the growth rate of the knowledge stock are mostly at low frequencies and, to some extent, at medium cycle frequencies, which is due to the high R\&D adjustment costs. Thus, most of the variation in TFP is attributed to the fluctuations in adopted knowledge.

Figure 1 plots the evolution of the model implied TFP growth (solid blue line) along with the adopted knowledge (dashed black line) and knowledge (red dotted line) components of TFP growth. These series are obtained extracting the corresponding smoothed series based on the posterior mode estimates. Consistent with variance decomposition above, TFP growth appears substantially more volatile with respect to the growth rate of technology itself. In principle, such large fluctuations could be explained by changes in the stationary component of TFP. However, it is evident that changes in the diffusion rate capture the bulk of the fluctuations in TFP growth as adopted knowledge tracks quite closely the fluctuations in TFP. In other words, this figure corroborates the finding that the most important margin for explaining TFP growth dynamics consists of changes in the diffusion rate of existing technology, as opposed to fluctuations in the 
accumulation of knowledge through $\mathrm{R} \& \mathrm{D}$ or exogenous fluctuations in technology as captured by the stationary technology shock.

It is then interesting to understand what forces drive the observed fluctuations. In order to address this question, Table 3 reports the variance decomposition with respect to the structural shocks that affect the macroeconomy. The top panel refers to the overall variance, while the middle and lower panels contain the variance decomposition at business and medium term cycle frequencies, respectively.

The first observation that is worth emphasizing is that shocks to the marginal efficiency of investment play a central role for all the observed variables included in our estimates. This is clear when analyzing the overall variance decomposition. In all cases, shocks to the marginal efficiency of investment explain more than $50 \%$ of the overall variance. Examining this result in more detail, it emerges that marginal efficiency of investment (MEI) shocks play a dominant role for for medium cycle fluctuations. At these frequencies, the marginal efficiency of investment explains around $70 \%$ of the variance for most of the endogenous variables, with a peak of $92 \%$ for the FFR. Given that the medium term frequencies account for more than $50 \%$ of the overall volatility, as explained above, it is not surprising that the marginal efficiency of investment plays such a central role for the overall variance decomposition. Furthermore, the marginal efficiency of investment plays a key role at business cycle frequencies for investment growth and, consequently, for GDP growth. This finding is in line with previous results by Justiniano, Primiceri, and Tambalotti (2010).

The dynamics of the endogenous components of TFP growth differ quite substantially from each other. For the knowledge growth component, shocks to the marginal efficiency of investment play a key role. This is due to fact that knowledge growth is very persistent and the MEI shocks are particularly important for medium-frequency fluctuations. In contrast, for adopted knowledge growth, the stationary technology shock explains around $30 \%$ of the overall volatility, while MEI and preference shocks both explain around 25\%. Notice that this result is not trivial because adopted knowledge does not include the stationary technology shock. Therefore, the observed variations derive from adjustment in the diffusion rate. Overall, these results suggest that stationary TFP shocks can have important effects at business cycle frequencies while low-frequency movements in growth are mostly driven by MEI shocks.

In fact, stationary technology shocks explain a sizeable fraction of consumption fluctuations at business cycle frequencies (around 19\%). Preference shocks also explain a sizeable fraction of consumption volatility at business cycle frequencies, but they are mostly irrelevant for medium- 
term fluctuations. As a result, preference shocks play a modest role for explaining the bulk of the overall consumption volatility. As the stationary TFP shocks drive most of the short run dynamics in real marginal costs, these shocks consequently explain most of the business cycle variation in inflation (around $70 \%$ ). The fact that the stationary technology shock explains the bulk of inflation business cycle fluctuations and at the same time has large effects on the growth rate of adopted technology creates and interesting link between inflationary shocks and growth that we will explore in Subsection 4.2. Finally, the stationary technology shocks are also important for the other observed variables, at both medium and business cycle frequencies, except for the FFR. In particular, for interest rate dynamics, shocks to the marginal efficiency of investment are most important because of the estimated large response of the FFR to GDP growth and inflation.

Overall, we provide new evidence supporting the importance of shocks to the marginal efficiency of investment for economic fluctuations, particularly at medium to low frequencies. As in Justiniano, Primiceri, and Tambalotti (2010) this shock is important for business cycle fluctuations of investment. However, our estimates suggest that this shock plays a key role to explain medium term fluctuations of all observed variables, and not just GDP and investment. Given that the medium-term frequencies explain most of the overall volatility, shocks to marginal efficiency of investment are therefore the driving force for the overall macroeconomic volatility of the observed variables. Our evidence is also consistent with the asset market literature, which shows that investment-specific shocks are an important source of systematic risk and therefore stock market returns (e.g., Papanikolaou (2011) and Kogan and Papanikolaou (2014)).

We find the transmission of a typical business cycle shock, such as the MEI shock, to medium cycle fluctuations interesting in light of the fact that Justiniano, Primiceri, and Tambalotti (2010) suggest that the MEI shock might capture frictions in financial markets that make more or less easy to finance investment plans. In our model, knowledge spillovers from R\&D accumulation and technology diffusion rates provide transmission channels of macroeconomic shocks to medium- and long-term growth. More broadly, our estimation suggests a tight link between business cycles and medium term fluctuations, which supports the findings of Comin and Gertler (2006). The role played by this shock for the lower frequency movements of consumption growth are also interesting in light of the long run risks literature (e.g., Bansal and Yaron (2004)) that focuses on the comovements between consumption growth and asset returns at longer horizons. We consider this a promising direction for future research. In the next section, we focus on impulse responses to better understand the propagation of the shocks. 


\subsection{Impulse responses}

This section illustrates the key model mechanisms through impulse response functions. Figure 2 displays impulse response functions from a positive shock to the marginal efficiency of physical investment. A good investment shock triggers more investment in physical capital. Given the complementarity of the factor inputs, a larger physical capital stock increases the marginal productivity of adopted knowledge, which leads to an increase in the diffusion of existing technology and a smooth increase in R\&D. Greater investment in R\&D raises TFP and also increases trend growth due to the spillover effects from knowledge accumulation. Note that the model also produces positive comovement in consumption and investment, which is sometimes a challenge for standard medium-size DSGE models such as Christiano, Eichenbaum, and Evans (2005). After a positive investment shock, the increase in $\mathrm{R} \& \mathrm{D}$ and technology diffusion amplify the output response by improving both the level and trend components of TFP persistently. Higher current and future levels of output consequently induce a positive consumption response. The positive commovement of macroeconomic quantities to investment shocks allow these shocks to be the main driver of business cycles and low-frequency movements in growth rates.

Figure 3 shows impulse response functions from a transitory negative shock to technology. This shock increases real marginal costs of production, which boosts inflation. Also, a negative technology shock reduces the marginal productivity of factor inputs, which reduces physical and $R \& D$ investment. Given high $R \& D$ adjustment costs, the $R \& D$ response is more gradual than the response of physical investment. Instead, technology diffusion rates decline sharply initially since it is less costly to adjust diffusion rates than $\mathrm{R} \& \mathrm{D}$, which is reflected in the drop in the level of adopted knowledge. The persistent decline in $\mathrm{R} \& \mathrm{D}$ implies a persistent decline in knowledge. It is worth emphasizing that while the technology shock is very transitory (see lower left panel), the effects on macroeconomic quantities are quite persistent, and is primarily due to the medium-term dynamics of adopted knowledge. In short, the model generates endogenous persistence in the cycle and trend components of macroeconomic variables.

Figure 4 displays the impulse response functions to a contractionary monetary policy shock. A tightening of monetary policy increases the FFR and lowers the price level. Due to sticky prices, aggregate demand falls and the real rate rises, which discourages investment in physical capital and $\mathrm{R} \& \mathrm{D}$. The decline in $\mathrm{R} \& \mathrm{D}$ and technology diffusion leads to a decline in TFP after a contractionary monetary policy shock, consistent with empirical evidence from Evans and dos Santos (2002). 
Further, the drop in R\&D lowers the trend component of TFP due to the endogenous growth channel. Note that response of $R \& D$ is significantly more persistent than the other macroeconomic variables, which is a reflection of the high $R \& D$ adjustment costs.

\section{Two key events}

In this section we analyze two key events in US economic history. We first focus on the Great Recession. Then, we move to revisit the Great Inflation and the productivity slowdown.

\subsection{The Great Recession}

The most recent recession has generated concerns about the possibility of a prolonged slowdown. Following the speech delivered by Larry Summers (Summers (2013)), some economists have become interested in the possibility of a "secular stagnation" similar to the one that characterized the aftermath of the Great Depression according to Hansen (1939). Eggertsson and Mehrotra (2014) builds a model that can deliver secular stagnation as a result of household deleveraging or a decline in the population growth rate. Gordon (2014) argues that the US might be heading toward a prolonged period of reduced growth. On the other hand, using projections from a calibrated model, Fernald (2014) finds that trend growth remained stable after the Great Recession.

Our model provides a useful framework to address these concerns from a quantitative point of view given the strong linkages between business cycle fluctuations and long term growth. Figure 5 analyzes the Great Recession through the lens of our model. The solid blue line reports smoothed estimates at the posterior mode for investment, knowledge growth, and the diffusion rate, $u_{n, t}$, over the past 15 years. The dashed black line describes a counterfactual simulation in which all policy shocks are set to zero since the beginning of the crisis. Specifically, starting from the first quarter of 2008 we set the filtered government expenditure shocks, monetary policy shocks, and inflation target shocks to zero.

The first aspect that emerges from this analysis is that while the recession has implied a significant fall in investment in physical capital, the growth rate for knowledge has been substantially less affected. Instead, the fall in investment has determined a significant and persistent decline in the diffusion rate of existing technology due to the decline in the marginal return of adopted technology. Interestingly, this pattern was reversed during the 2001 recession. In the 2001 recession, the economy experienced a relatively small fall of investment in physical capital, a substantial fall 
in the accumulation of knowledge (after the large accumulation of $\mathrm{R} \& \mathrm{D}$ during the IT boom in the 1990's), and only a relatively modest decline in the diffusion rate of existing technology. The knowledge growth rate recovered very slowly and reached levels similar to 2001 only after several years.

These results have important implications for the long-term consequences of the current recession. On the one hand, it seems that the low-frequency trend component (knowledge growth) has not been substantially affected, implying that long-run growth remained stable. On the other hand, as we have shown in Subsection 3.3, the consequences of a slowdown in the diffusion rate of technology can persist for many years, implying that it might take a significant amount of time before the economy closes the gap with respect to the trend component.

In this respect, it is interesting to analyze the role of policymakers' behavior. Modeling unconventional monetary policy or changes in policy rules is beyond the scope of the paper. However, it is still instructive to study the implications of policy shocks. The counterfactual simulation reported in Figure 5 shows that absent policy shocks, the growth rate of knowledge would have been only mildly affected, but the extent of the recovery in investment and diffusion of existing technology would have been much more contained.

These results have important implications for the role of policy intervention during recessions. In models with exogenous growth, TFP does not depend on policymakers' actions. As a result, these models generally predict a steady and relatively fast return to the trend, independent from the actions undertaken by the fiscal and monetary authorities. Instead, in the present model sustaining demand during a severe recession can deeply affect the medium and long term consequences for the economy. Policymakers cannot intervene each period to permanently alter the trend growth rate of the economy. ${ }^{8}$ This would violate the notion of the equilibrium steady state and be subject to the Lucas critique. However, policymakers can substantially reduce the long-term consequences of a recession.

\subsection{The Great Inflation and the productivity slowdown}

The Great Inflation and the productivity slowdown that occurred in the 1970s have attracted a lot of attention in the literature. Several explanations have been proposed for why inflation rose during the 1960s and 1970s. Orphanides (2002), Primiceri (2006), and Sargent, Williams, and Zha (2006) have focused on Central bankers' misperceptions about the state and structure of the economy,

\footnotetext{
${ }^{8}$ See Barro and Sala-i-Martin (1992) for a model where public finance can affect the steady state growth rate.
} 
Clarida, Gali, and Gertler (2000) and Lubik and Schorfheide (2004) provide support in favor of violations of the Taylor principle, and Cochrane (1998), Sims (2011), and Bianchi and Ilut (2012) emphasize a dysfunctional interaction between the monetary and fiscal authorities.

During the 1970s movements in inflation exhibited both strong low-frequency and business cycle components. The former has been often explained in light of a persistent productivity slowdown that arguably led to changes in policymakers' reaction functions. The latter was mostly determined by two oil crises that occurred in 1973/1974 and in 1979. In what follows, we will use our model to highlight the link between these two components.

Figure 6 reports the series for inflation and the model implied growth rate for adopted knowledge based on the parameter values from the posterior mode. The red dashed line corresponds to the actual data, while the solid blue line captures the variation in the variables that is due to the stationary technology shocks. This is obtained by using a counterfactual simulation in which all shocks except the stationary technology shocks are set to zero. It is worth emphasizing that adopted knowledge does not include the stationary technology shock:

$$
\text { TFP }=\underset{\text { Stat. tech. shock }}{A_{t}} * \underset{u_{t}^{n} \bar{N}_{t-1}}{\text { Adopted knowledge }}
$$

Therefore, movements in the growth rate of adopted knowledge are not the result of an accounting identity but derive from the endogenous responses of the technology diffusion rate, $u_{t}^{n}$, and the stock of knowledge, $\bar{N}_{t-1}$, to a stationary technology shock, $A_{t}$. We focus on this component, as opposed to $\bar{N}_{t-1}$ only, because as shown above it captures the bulk of TFP fluctuations.

The counterfactual series for inflation tracks very closely fluctuations of inflation at high frequencies. This is particularly visible in the 1970s, but also at the beginning of the sample and toward the end of the 1990s. This is in line with the variance decomposition results that show that stationary technology shocks explain up to $70 \%$ of inflation fluctuations at business cycle frequencies. However, the right panel shows that these shocks also have a visible impact on the persistent component of TFP. In other words, the results suggest that a significant fraction of the decline in measured productivity that occurred in the '70s can be explained in light of short-lived inflationary oil shocks because of their impact on the growth rate of adopted knowledge. These results are in line with the evidence presented in Section 3.3: A stationary technology shock has an immediate and short-lived impact on inflation, but has a prolonged effect on the diffusion rate of existing technology and a very persistent effect on the accumulation of knowledge itself. 
When TFP is endogenous, the consequences of the oil shocks of the 1970s are quite different than in the exogenous TFP setting. While all shocks have an impact on TFP through the knowledge and diffusion components, stationary technology shocks are different to the extent that they move growth and inflation in opposite directions. As a result, our model suggests a link between the productivity slowdown, a low frequency phenomenon, and short lived inflationary shocks, the oil shocks. While other factors might have contributed to the productivity slowdown, we believe that a model featuring endogenous growth introduces a new dimension for the analysis of the events of the 1970s. This is for two reasons. First, the fact that a short-lived inflationary shock can have persistent consequences on the trend can easily lead to misperceptions, that, in turn, might cause policy mistakes. Second, due to the link between the high- and low-frequency fluctuations, policymakers might be tempted to accommodate these shocks in order to mitigate their long-run consequences on growth. In both cases, policy makers' actions could lead to a progressive increase in the low frequency component of inflation.

\section{Conclusions}

In this paper, we build and estimate a medium-size DSGE model that features endogenous growth and technology diffusion. Positive externalities from knowledge accumulation provide a economic channel linking business cycle shocks to long-run growth through the trend component of TFP. The endogenous technology diffusion rates provide a strong propagation channel at medium-term frequencies through adopted knowledge. We find that shocks to the marginal efficiency of physical investment explain the majority of the volatility for all macroeconomic variables. This is because these shocks have large effects at medium-term frequencies that, in turn, capture the bulk of the overall volatility. The endogenous growth margin also helps the model to generate positive comovement in consumption and investment in response to a MEI shock, which is sometimes a challenge for standard DSGE models. More broadly, our model estimation suggests strong linkages between business cycle fluctuations and low-frequency movements in aggregate growth rates.

We then use our estimated model to interpret two major economic events and analyze their longrun consequences. During the Great Recession, we show that while there was a significant decline in investment and in the diffusion rate of technology, the trend component was less effected. In the context of our model, this implies that the most recent recession had severe consequences in the short- and medium-term, but long-run trend growth remained stable. The opposite was true during 
the 2001 recession. We also show that large, but short-lived inflationary shocks, like the oil shocks in the 1970s, contributed to the productivity slowdown of the 1970s due to their persistent effects on adopted knowledge and R\&D accumulation. In short, our paper highlights the importance of studying growth and business cycles in a unified setting for understanding macroeconomic dynamics. 


\section{Appendix A. System of linearized equations}

This appendix reports the linearized system of equations used for the estimation.

1. Firms, "marginal cost" in terms of both factor costs:

$$
\begin{aligned}
(1+(1-\alpha) \eta) \widehat{m c}_{t}= & \alpha \widehat{r}_{t}^{k}+(1-\alpha)\left(\widehat{w}_{t}-\widehat{a}_{t}\right)-(1-\alpha) \eta\left(\frac{y}{y+F}\right) \widehat{y}_{t} \\
& +\left[(\eta-1)(1-\alpha) \frac{1}{\sigma_{n}}+\eta(1-\alpha)\right] \widehat{r}_{t}^{n}+(\eta-1)(1-\alpha) \widehat{\mu}_{n, t}
\end{aligned}
$$

2. Firms, marginal cost in terms of rental rate of capital:

$$
\widehat{m c}_{t}=\widehat{r}_{t}^{k}-(1-\alpha)\left(\widehat{a}_{t}+\widehat{u}_{t}^{n}+\widehat{L}_{t}-\widehat{u}_{t}^{k}-\widehat{\bar{k}}_{t-1}\right)
$$

3. Firms, real rental rate of $R \& D$ capital:

$$
\widehat{r}_{t}^{n}=\widehat{m c}_{t}+\alpha\left(u_{t}^{k}+\bar{k}_{t-1}-u_{t}^{n}\right)+(1-\alpha)\left(\widehat{a}_{t}+\widehat{L}_{t}\right)
$$

4. Phillips curve:

$$
\hat{\pi}_{t}=\left(\frac{1}{1+\beta \iota_{p}} \frac{1-\zeta_{p}}{\zeta_{p}}\right)\left(\frac{1-\zeta_{p} \beta}{\tilde{\theta}_{1}}\right) \widehat{m c}_{t}+\left(\frac{\iota_{p}}{1+\beta \iota_{p}}\right) \hat{\pi}_{t-1}+\left(\frac{\beta}{1+\beta \iota_{p}}\right) E_{t} \hat{\pi}_{t+1}
$$

where $\tilde{\theta}_{1}=\left(1-\frac{(1-\alpha) \eta}{1+(1-\alpha) \eta} \frac{\lambda_{f}}{\lambda_{f}-1} \frac{y}{y+F}\right)$.

5. Households, consumption:

$$
\widehat{\lambda}_{n, t}=-\frac{\Phi_{c}}{M_{n}-\Phi_{c}} \widehat{\mu}_{n, t}-\frac{M_{n}}{M_{n}-\Phi_{c}} \widehat{c}_{t}+\frac{\Phi_{c}}{M_{n}-\Phi_{c}} \widehat{c}_{t-1}
$$

6. Households, labor:

$$
\hat{w}_{t}=\sigma_{L} \widehat{L}_{t}-\hat{\lambda}_{n, t}
$$

7. Households, bonds:

$$
0=\zeta_{C, t}\left(1-\rho_{\zeta_{C}}\right)+\widehat{\lambda}_{n, t}-E_{t} \widehat{\lambda}_{n, t+1}-\widehat{R}_{t}+E_{t} \widehat{\pi}_{t+1}+E_{t} \widehat{\mu}_{n, t+1}
$$


8. Households, physical capital:

$$
0=\zeta_{C, t}\left(1-\rho_{\zeta_{C}}\right)+\hat{\lambda}_{n, t}-E_{t} \hat{\lambda}_{n, t+1}-E_{t} \hat{R}_{t+1}^{k}+E_{t} \widehat{\pi}_{t+1}+E_{t} \widehat{\mu}_{n, t+1}
$$

9. Return on physical capital: then

$$
\widehat{R}_{t}^{k}=\frac{\Pi}{q^{k} R^{k}} r^{k}\left(\widehat{r}_{t}^{k}+\widehat{u}_{t}^{k}\right)+\frac{\Pi}{R^{k}}\left(1-\delta_{k}\right) \widehat{q}_{t}^{k}+\widehat{\pi}_{t}-\widehat{q}_{t-1}^{k}
$$

where $q^{k}=1$.

10. Households, investment in physical capital:

$$
\begin{aligned}
0= & \widehat{q}_{t}^{k}+\widehat{\zeta} \Upsilon, t_{k}-\Psi_{k}^{\prime \prime} M_{n}^{2}(1+\beta) \widehat{i}_{t}+\widehat{\zeta}_{I, t}-\Psi_{k}^{\prime \prime} M_{n}^{2} \hat{\mu}_{n, t} \\
& \Psi_{k}^{\prime \prime} M_{n}^{2} \widehat{i}_{t-1}+\beta M_{n}^{2} \Psi_{k}^{\prime \prime} E_{t}\left[\widehat{i}_{t+1}\right]+\beta M_{n}^{2} \Psi_{k}^{\prime \prime} E_{t}\left[\hat{\mu}_{n, t+1}\right]
\end{aligned}
$$

11. Households, physical capital utilization:

$$
\widehat{u}_{t}^{k}=\widehat{\widetilde{r}}_{t}^{k} \frac{1}{\sigma_{A}}
$$

12. Households, physical capital accumulation:

$$
\widehat{\bar{k}}_{t}=\frac{1-\delta_{k}}{M_{n}}\left(\hat{\bar{k}}_{t-1}-\hat{\mu}_{n, t}\right)+\frac{i}{\bar{k}}\left(\hat{i}_{t}+\widehat{\zeta}_{I, t}\right)
$$

13. Households, R\&D capital:

$$
\left(1-\rho_{\zeta_{C}}\right) \widehat{\zeta}_{C, t}+\widehat{\lambda}_{n, t}=E_{t} \widehat{\lambda}_{n, t+1}+E_{t} \widehat{R}_{t+1}^{n}-E_{t} \widehat{\pi}_{t+1}-E_{t} \widehat{\mu}_{n, t+1}
$$

14. Return on R\&D capital:

$$
\widehat{R}_{t}^{n}=\frac{\Pi}{q^{n} R^{n}} r^{n}\left(1+\frac{1}{\sigma_{n}}\right) \widehat{r}_{t}^{n}+\frac{\Pi}{R^{n}}\left(1-\delta_{n}\right) \widehat{q}_{t}^{n}+\widehat{\pi}_{t}-\widehat{q}_{t-1}^{k}
$$

where $q^{n}=1$. 
15. Households, investment in R\&D capital:

$$
\begin{aligned}
0= & \widehat{q}_{t}^{n}-\Psi_{n}^{\prime \prime} M_{n}^{2}(1+\beta) \widehat{s}_{t}+\widehat{\zeta}_{S, t}-\Psi_{n}^{\prime \prime} M_{n}^{2} \hat{\mu}_{n, t} \\
& +\Psi_{n}^{\prime \prime} M_{n}^{2} \widehat{s}_{t-1}+\beta M_{n}^{2} \Psi_{n}^{\prime \prime} E_{t}\left[\widehat{s}_{t+1}\right]+\beta M_{n}^{2} \Psi_{n}^{\prime \prime} E_{t}\left[\hat{\mu}_{n, t+1}\right]
\end{aligned}
$$

16. Households, Knowledge diffusion:

$$
\widehat{u}_{t}^{n}=\widehat{\widetilde{r}}_{t}^{n} \frac{1}{\sigma_{n}}
$$

17. Households, Knowledge accumulation:

$$
\widehat{\mu}_{n, t}=\left(\left(1-\delta_{n}\right)^{-1} M_{n}-1\right)\left(\widehat{s}_{t}+\widehat{\zeta}_{S, t}\right)
$$

18. Government expenditure:

$$
\hat{g}_{t}=\rho_{g} \hat{g}_{t-1}+\sigma_{g} \epsilon_{g, t}
$$

19. GDP:

$$
\widehat{y}_{t}^{G}=\frac{c}{y^{G}} \widehat{c}_{t}+\eta_{G} \widehat{g}_{t}+\frac{i}{y^{G}}\left(\widehat{i}_{t}-\widehat{\zeta} \Upsilon, t\right)+\frac{s}{y^{G}} \widehat{s}_{t}
$$

where $\eta_{G}=G / Y^{G}$.

20. Resource constraint:

$$
\begin{aligned}
c \widehat{c}_{t}+i\left(\widehat{i}_{t}-\widehat{\zeta} \Upsilon, t\right)+s \widehat{s}_{t}+\eta_{G} y \widehat{g}_{t}= & (y+F)\left[(1-\alpha)\left(a_{t}+\widehat{L}_{t}\right)+\alpha \widehat{\bar{k}}_{t-1}-\widehat{\mu}_{n, t}\right] \\
& +\left[(y+F) \alpha-r^{k} \bar{k} M_{n}^{-1}\right] \frac{1}{\sigma_{A}} \widehat{\widehat{r}}_{t}^{k} \\
& +\left[(y+F)(1-\alpha)-r^{n} M_{n}^{-1}\right] \frac{1}{\sigma_{n}} \widehat{r}_{t}^{n}
\end{aligned}
$$

21. Monetary Policy:

$$
\widetilde{R}_{t}=\rho_{R} \widetilde{R}_{t-1}+\left(1-\rho_{R}\right)\left[\phi_{\pi}\left(\widehat{\pi}_{t}-\widehat{\pi}_{t}^{*}\right)+4 \phi_{d y}\left(\widehat{y}_{t}^{G}-\widehat{y}_{t-1}^{G}+\widehat{\mu}_{n, t}\right)+\phi_{y} \widehat{y}_{t}^{G}\right]+\sigma_{R} \epsilon_{R . t}
$$


22. Three equations describing the shocks to $\zeta_{S, t}, \zeta_{C, t}$ and $\zeta_{I, t}$ :

$$
\log \left(\zeta_{X, t}\right)=\rho_{\zeta_{X}} \log \left(\zeta_{X, t-1}\right)+\sigma_{\zeta_{X}}\left(\xi_{t}^{v o}\right) \varepsilon_{\zeta_{X}, t}
$$

23. Productivity shock:

$$
a_{t}=(1-\rho) a^{\star}+\rho_{a} a_{t-1}+\sigma_{a} \epsilon_{a, t}
$$

24. Time varying inflation target

$$
\pi_{t}^{*}=\rho_{\pi} \pi_{t-1}^{*}+\sigma_{\pi} \epsilon_{\pi, t}
$$




\section{Appendix B. Convergence}

Table 4 reports results based on the Brooks-Gelman-Rubin potential reduction scale factor using within and between variances based on the four multiple chains used in the paper. The eight chains

consist of 2,700,000 draws each (1 every 1000 draws is saved). The numbers are well below the 1.1 benchmark value used as an upper bound for convergence. 


\section{References}

Aghion, P., U. Akcigit, P. Howitt, 2013. What do we learn from Schumpeterian growth theory?. Unpublished working paper. National Bureau of Economic Research.

Aghion, P., P. Howitt, 1992. A model of growth through creative destruction. Econometrica 60(2), $323-351$.

Aguiar, M., G. Gopinath, 2007. Emerging Market Business Cycles: The Cycle Is the Trend. Journal of Political Economy 115, 69-102.

Alesina, A., S. Ardagna, 2010. Large changes in fiscal policy: taxes versus spending. in Tax Policy and the Economy, Volume 24. The University of Chicago Press pp. 35-68.

Altig, D., L. J. Christiano, M. Eichenbaum, J. Linde, 2011. Firm-specific capital, nominal rigidities and the business cycle. Review of Economic Dynamics 14(2), 225-247.

Bai, Y., J.-V. Rios-Rull, K. Storesletten, 2012. Demand shocks as productivity shocks. Federal Reserve Board of Minneapolis.

Bansal, R., A. Yaron, 2004. Risks for the long run: A potential resolution of asset pricing puzzles. The Journal of Finance 59(4), 1481-1509.

Barlevy, G., 2004. The Cost of Business Cycles Under Endogenous Growth. The American Economic Review 94(4), 964-990.

Barro, R., R. King, 1984. Time-Separable Preferences and Intertemporal-Substitution Models of Business Cycles. Quarterly Journal of Economics.

Barro, R. J., 1991. Economic Growth in a Cross Section of Countries. The Quarterly Journal of Economics 106(2), 407-443.

Barro, R. J., X. Sala-i-Martin, 1992. Public finance in models of economic growth. The Review of Economic Studies 59(4), 645-661.

Barro, R. J., X. Sala-i-Martin, 1997. Technological Diffusion, Convergence, and Growth. Journal of Economic Growth.

Basu, S., D. N. Weil, 1998. Appropriate Technology and Growth*. The Quarterly Journal of Economics 113(4), 1025-1054. 
Bianchi, F., 2013. Regime switches, agents' beliefs, and post-world war ii us macroeconomic dynamics. The Review of Economic Studies p. rds032.

Bianchi, F., C. Ilut, 2012. Monetary/Fiscal Policy Mix and Agents' Beliefs. CEPR discussion paper 9645, NBER working paper 20194.

Bianchi, F., L. Melosi, 2014. Escaping the Great Recession. CEPR, .

Christiano, L. J., M. Eichenbaum, C. L. Evans, 2005. Nominal rigidities and the dynamic effects of a shock to monetary policy. Journal of political Economy 113(1), 1-45.

Christiano, L. J., M. S. Eichenbaum, M. Trabandt, 2014. Understanding the Great Recession. Unpublished working paper. National Bureau of Economic Research.

Clarida, R., J. Gali, M. Gertler, 2000. Monetary Policy Rules and Macroeconomic Stability: Evidence and Some Theory. Quarterly Journal of Economics 115, 147-180.

Cochrane, J. H., 1998. A Frictionless Model of U.S. Inflation. in NBER Macroeconomics Annual 1998, ed. by B. S. Bernanke, and J. J. Rotemberg. MIT Press Cambridge, MA pp. 323-384.

Comin, D., 2009. On the integration of growth and business cycles. Empirica 36(2), 165-176.

Comin, D., M. Gertler, 2006. Medium Term Business Cycles. American Economic Review.

Comin, D., B. Hobijn, 2004. Cross-country technology adoption: making the theories face the facts. Journal of Monetary Economics 51(1), 39-83.

Comin, D., B. Hobijn, 2010a. An Exploration of Technology Diffusion. The American Economic Review 100(5), 2031-2059.

Comin, D. A., M. Gertler, A. M. Santacreu, 2009. Technology innovation and diffusion as sources of output and asset price fluctuations. Unpublished working paper. National Bureau of Economic Research.

Comin, D. A., B. Hobijn, 2010b. Technology diffusion and postwar growth. Unpublished working paper. .

Del Negro, M., F. Schorfheide, F. Smets, R. Wouters, 2007. On the fit of new Keynesian models. Journal of Business \& Economic Statistics 25(2), 123-143. 
Eggertsson, G., N. Mehrotra, 2014. A Model of Secular Stagnation. .

Evans, C. L., F. T. dos Santos, 2002. Monetary policy shocks and productivity measures in the G-7 countries. Portuguese Economic Journal 1(1), 47-70.

Fernald, J., 2014. Productivity and potential output before, during, and after the Great Recession. in NBER Macroeconomics Annual 2014, Volume 29. University of Chicago Press.

Gordon, R. J., 2010. Revisiting US productivity growth over the past century with a view of the future. Unpublished working paper. National Bureau of Economic Research.

Gordon, R. J., 2014. The Demise of US Economic Growth: Restatement, Rebuttal, and Reflections. Unpublished working paper. National Bureau of Economic Research.

Griliches, Z., 1992. The search for R\&D spillovers. Unpublished working paper. National Bureau of Economic Research.

Grossman, G., E. Helpman, 1991. Quality ladders and product cycles. Quarterly Journal of Economics 106(2), 557-586.

Guajardo, J., D. Leigh, A. Pescatori, 2014. Expansionary Austerity? International Evidence. Journal of the European Economic Association.

Guerron-Quintana, P. A., R. Jinnai, 2013. Liquidity, Trends and the Great Recession. .

Hansen, A. H., 1939. Economic progress and declining population growth. The American Economic Review pp. 1-15.

Jovanovic, B., P. L. Rousseau, 2005. General purpose technologies. Handbook of economic growth $1,1181-1224$.

Justiniano, A., G. E. Primiceri, 2008. The Time-Varying Volatility of Macroeconomic Fluctuations. The American Economic Review 98(3), 604-641.

Justiniano, A., G. E. Primiceri, A. Tambalotti, 2010. Investment shocks and business cycles. Journal of Monetary Economics 57(2), 132-145.

Justiniano, A., G. E. Primiceri, A. Tambalotti, 2011. Investment shocks and the relative price of investment. Review of Economic Dynamics 14(1), 102-121. 
Kogan, L., D. Papanikolaou, 2014. Growth opportunities, technology shocks, and asset prices. The Journal of Finance 69(2), 675-718.

Kung, H., 2014. Macroeconomic Linkages Between Monetary Policy and the Term Structure of Interest Rates. Journal of Financial Economics. Forthcoming.

Kung, H., L. Schmid, 2014. Innovation, growth, and asset prices. Journal of Finance. Forthcoming.

Lubik, T., F. Schorfheide, 2004. Testing for Indeterminacy: An Application to U.S. Monetary Policy. American Economic Review 94(1), 190-217.

McGrattan, E. R., E. C. Prescott, 2010. Unmeasured Investment and the Puzzling US Boom in the 1990s. American Economic Journal: Macroeconomics 2(4), 88-123.

Orphanides, A., 2002. Monetary Policy Rules and the Great Inflation. 92(2), 115-120 (Proceedings issue).

Papanikolaou, D., 2011. Investment shocks and asset prices. Journal of Political Economy 119(4), 639-685.

Parente, S. L., E. C. Prescott, 1994. Barriers to technology adoption and development. Journal of political Economy pp. 298-321.

Peretto, P., 1999. Industrial development, technological change, and long-run growth. Journal of Development Economics 59(2), 389-417.

Primiceri, G., 2006. Why Inflation Rose and Fell: Policymakers' Beliefs and US Postwar Stabilization Policy. The Quarterly Journal of Economics 121(August), 867-901.

Romer, P. M., 1990. Endogenous technological change. Journal of political Economy pp. S71-S102.

Sargent, T., N. Williams, T. Zha, 2006. Shocks and Government Beliefs: The Rise and Fall of American Inflation. 96(4), 1193-1224.

Sims, C. A., 2011. Stepping on a Rake: The Role of Fiscal Policy in the Inflation of the 1970's. European Economic Review 55(1), 48-56.

Smets, F., R. Wouters, 2007. Shocks and Frictions in US Business Cycles: A Bayesian DSGE Approach. The American Economic Review 97(3), 586-606.

Summers, L., 2013. Why Stagnation Might Prove to be the New Normal. The Financial Times. 


\begin{tabular}{c|cccc|ccc} 
Parameter & Mode & Mean & $5 \%$ & $95 \%$ & Type & Mean & St.dev. \\
\hline \hline$\phi_{\pi}$ & 1.3448 & 1.3565 & 1.2216 & 1.5034 & $N$ & 2 & 0.3 \\
$\phi_{d y}$ & 0.1591 & 0.1591 & 0.1307 & 0.1856 & $G$ & 0.3 & 0.15 \\
$\rho_{R}$ & 0.7495 & 0.7532 & 0.7143 & 0.7884 & $B$ & 0.6 & 0.2 \\
$\eta$ & 0.0109 & 0.0186 & 0.0071 & 0.0373 & $B$ & 0.2 & 0.1 \\
$\Psi_{n}^{\prime \prime}$ & 77.2272 & 90.0391 & 65.0200 & 120.0458 & $G$ & 15 & 10 \\
$\sigma_{n}$ & 0.0047 & 0.0080 & 0.0017 & 0.0186 & $G$ & 1.5 & 1 \\
$\Psi_{k}^{\prime \prime}$ & 1.0715 & 1.2146 & 0.7760 & 1.7796 & $G$ & 4 & 3 \\
$\sigma_{k}$ & 0.4772 & 0.5631 & 0.3371 & 0.9718 & $G$ & 1.5 & 1 \\
$\sigma_{L}$ & 1.6871 & 1.5339 & 0.7103 & 2.4639 & $G$ & 2 & 0.75 \\
$\xi_{p}$ & 0.7513 & 0.7665 & 0.7084 & 0.8175 & $B$ & 0.5 & 0.1 \\
$\iota_{p}$ & 0.5044 & 0.5588 & 0.2855 & 0.8325 & $B$ & 0.5 & 0.2 \\
$\rho_{\zeta_{I}}$ & 0.9832 & 0.9838 & 0.9775 & 0.9895 & $B$ & 0.5 & 0.2 \\
$\rho_{\zeta_{C}}$ & 0.0595 & 0.0834 & 0.0257 & 0.1585 & $B$ & 0.5 & 0.2 \\
$\rho_{\pi}$ & 0.4576 & 0.4491 & 0.3200 & 0.5761 & $B$ & 0.8 & 0.1 \\
$\rho_{\zeta_{S}}$ & 0.7347 & 0.7038 & 0.6230 & 0.7861 & $B$ & 0.5 & 0.2 \\
$\rho_{a}$ & 0.7551 & 0.7330 & 0.6300 & 0.8047 & $B$ & 0.5 & 0.2 \\
$100 \pi^{*}$ & 0.5434 & 0.5448 & 0.4658 & 0.6235 & $N$ & 0.5 & 0.05 \\
$100\left(\beta^{-1}-1\right)$ & 0.1639 & 0.1704 & 0.1219 & 0.2252 & $G$ & 0.25 & 0.05 \\
$\Phi_{c}$ & 0.8862 & 0.8865 & 0.8644 & 0.9072 & $B$ & 0.7 & 0.2 \\
$\lambda_{f}-1$ & 0.0741 & 0.0759 & 0.0437 & 0.1140 & $G$ & 0.15 & 0.05 \\
$\delta_{k}$ & 0.0190 & 0.0189 & 0.0151 & 0.0229 & $B$ & 0.03 & 0.01 \\
$\delta_{n}$ & 0.0011 & 0.0013 & 0.0004 & 0.0025 & $B$ & 0.2 & 0.1 \\
$a^{*}$ & -1.0522 & -1.3865 & -2.0848 & -0.6635 & $N$ & 0 & 0.5 \\
$\alpha$ & 0.2625 & 0.2616 & 0.2324 & 0.2919 & $B$ & 0.3 & 0.05 \\
\hline $100 \sigma_{R}$ & 0.1711 & 0.1710 & 0.1419 & 0.1998 & $I G$ & 0.5 & 0.5 \\
$100 \sigma_{\zeta_{I}}$ & 4.6810 & 4.9405 & 3.9398 & 6.0949 & $I G$ & 2 & 2 \\
$100 \sigma_{\zeta_{C}}$ & 2.9609 & 3.0803 & 2.5113 & 3.7657 & $I G$ & 2 & 2 \\
$100 \sigma_{\pi}$ & 0.4545 & 0.4660 & 0.3819 & 0.5626 & $I G$ & 2 & 2 \\
$100 \sigma \Upsilon$ & 0.7122 & 0.7163 & 0.6642 & 0.7736 & $I G$ & 2 & 2 \\
$100 \sigma_{\zeta_{S}}$ & 24.6905 & 31.6596 & 20.3170 & 45.4888 & $I G$ & 2 & 2 \\
$100 \sigma_{a}$ & 1.6360 & 1.9725 & 1.2981 & 2.8262 & $I G$ & 2 & 2 \\
$100 \sigma_{g}$ & 3.0155 & 3.0325 & 2.8115 & 3.2740 & $I G$ & 2 & 2 \\
\hline $100 \sigma_{I N F}$ & 0.2428 & 0.2437 & 0.1989 & 0.2825 & $I G$ & .05 & .1 \\
\hline \hline & & & & & & & \\
\hline
\end{tabular}

Table 1: Posterior modes, means, 90\% error bands, and priors of the model parameters. 


\begin{tabular}{r|ccc} 
& Long & Medium & Business \\
\hline \hline GDP growth & 13.38 & 42.96 & 43.34 \\
& $(11.31,15.79)$ & $(40.24,45.59)$ & $(40.18,46.58)$ \\
Inflation & 17.07 & 52.69 & 29.56 \\
& $(14.06,20.91)$ & $(46.86,57.23)$ & $(22.56,38.55)$ \\
FFR & 24.17 & 66.79 & 8.85 \\
& $(20.60,28.52)$ & $(63.44,69.54)$ & $(7.61,10.27)$ \\
Investment growth & 3.93 & 46.51 & 49.36 \\
& $(2.96,5.27)$ & $(43.42,49.46)$ & $(46.00,52.66)$ \\
Consumption growth & 28.61 & 52.50 & 18.56 \\
& $(24.83,32.95)$ & $(48.70,56.04)$ & $(15.97,21.41)$ \\
R\&D growth & 26.02 & 59.40 & 14.05 \\
& $(21.53,31.16)$ & $(54.75,63.77)$ & $(11.07,17.54)$ \\
\hline TFP growth & 4.85 & 18.12 & 76.32 \\
& $(3.81,6.00)$ & $(14.57,21.69)$ & $(72.04,80,60)$ \\
Adopted knowledge growth & 4.35 & 16.55 & 78.43 \\
& $(3.45,5.36)$ & $(13.49,19.72)$ & $(74.65,82.09)$ \\
Knowledge growth & 68.14 & 23.06 & 8.20 \\
& $(63.55,72.26)$ & $(19.91,26.59)$ & $(5.00,12.82)$ \\
\hline \hline
\end{tabular}

Table 2: Median and 90\% error bands for the model-implied variance across different frequency intervals. Long term: Cycles of more than 50 years. Medium term cycle: Cycles between 8 and 50 years, Business cycle: Cycles between .5 and 8 years. 

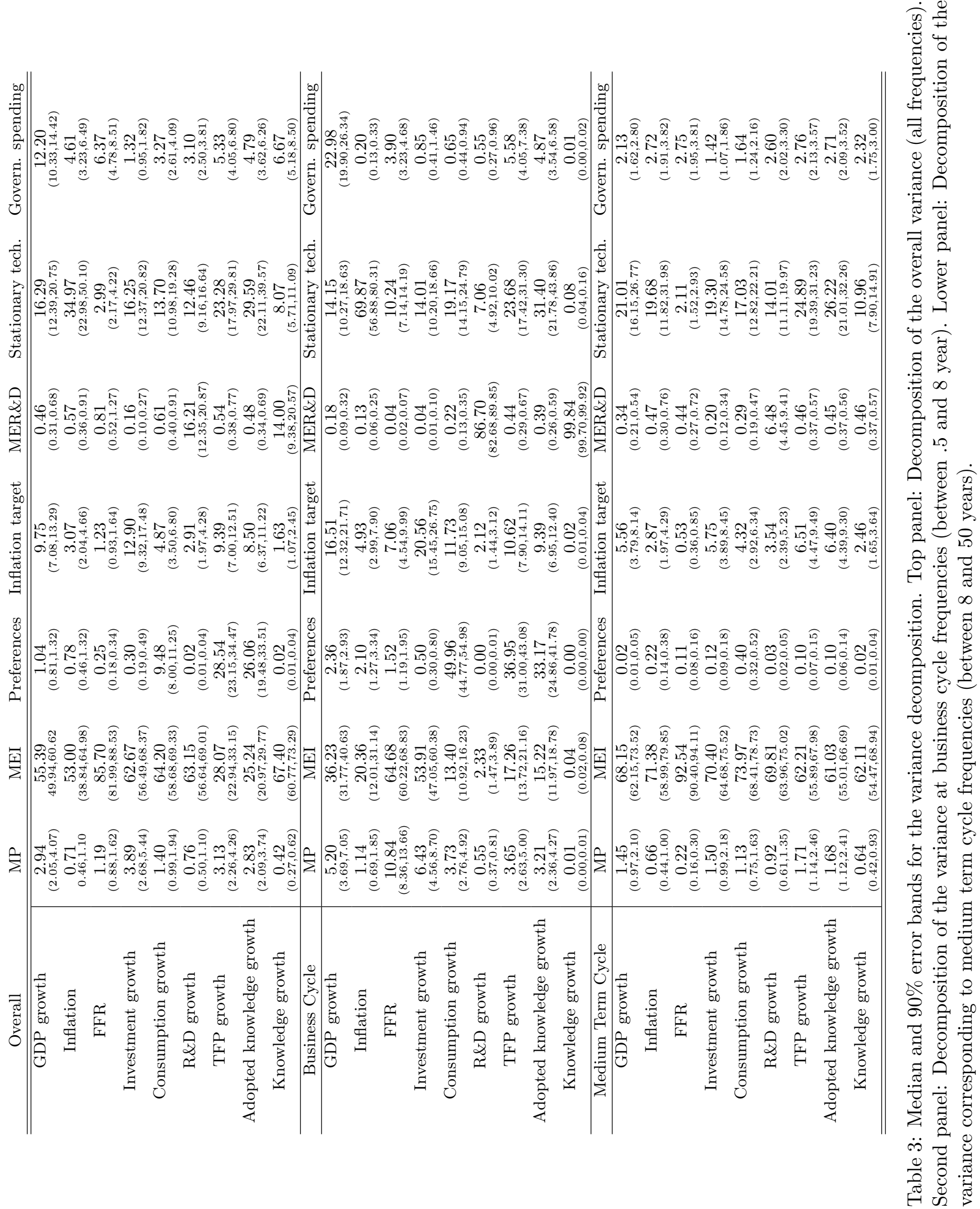
Potential Scale Reduction Factor

\begin{tabular}{cc|cc|cc|cc}
\hline \hline Parameter & PSRF & Parameter & PSRF & Parameter & PSRF & Parameter & PSRF \\
\hline$\phi_{\pi}$ & 1.00 & $\xi_{p}$ & 1.00 & $100\left(\beta^{-1}-1\right)$ & 1.00 & $100 \sigma_{\zeta_{I}}$ & 1.01 \\
$\phi_{d y}$ & 1.00 & $\iota_{p}$ & 1.01 & $\Phi_{c}$ & 1.01 & $100 \sigma_{\zeta_{C}}$ & 1.01 \\
$\rho_{R}$ & 1.00 & $\rho_{\zeta_{I}}$ & 1.00 & $\lambda_{f}-1$ & 1.00 & $100 \sigma_{\pi}$ & 1.00 \\
$\eta$ & 1.03 & $\rho_{\zeta_{C}}$ & 1.00 & $\delta_{k}$ & 1.00 & $100 \sigma_{\Upsilon}$ & 1.00 \\
$S_{N}^{\prime \prime}$ & 1.01 & $\rho_{\pi}$ & 1.00 & $\delta_{n}$ & 1.00 & $100 \sigma_{\zeta_{S}}$ & 1.00 \\
$S_{K}^{\prime \prime}$ & 1.01 & $\rho_{\zeta_{S}}$ & 1.00 & $a^{*}$ & 1.04 & $100 \sigma_{a}$ & 1.00 \\
$\sigma_{A}$ & 1.03 & $\rho_{a}$ & 1.01 & $\alpha$ & 1.00 & $100 \sigma_{g}$ & 1.00 \\
$\sigma_{N}$ & 1.01 & $100 \pi^{*}$ & 1.00 & $\sigma_{L}$ & 1.02 & $100 \sigma_{I N F}$ & 1.00 \\
\hline \hline
\end{tabular}

Table 4: The table reports the Gelman-Rubin Potential Scale Reduction Factor (PSRF) for four chains of 2,700,000 draws each (1 every 1000 is stored). Values below 1.1 are regarded as indicative of convergence. 
Figure 1: TFP Growth

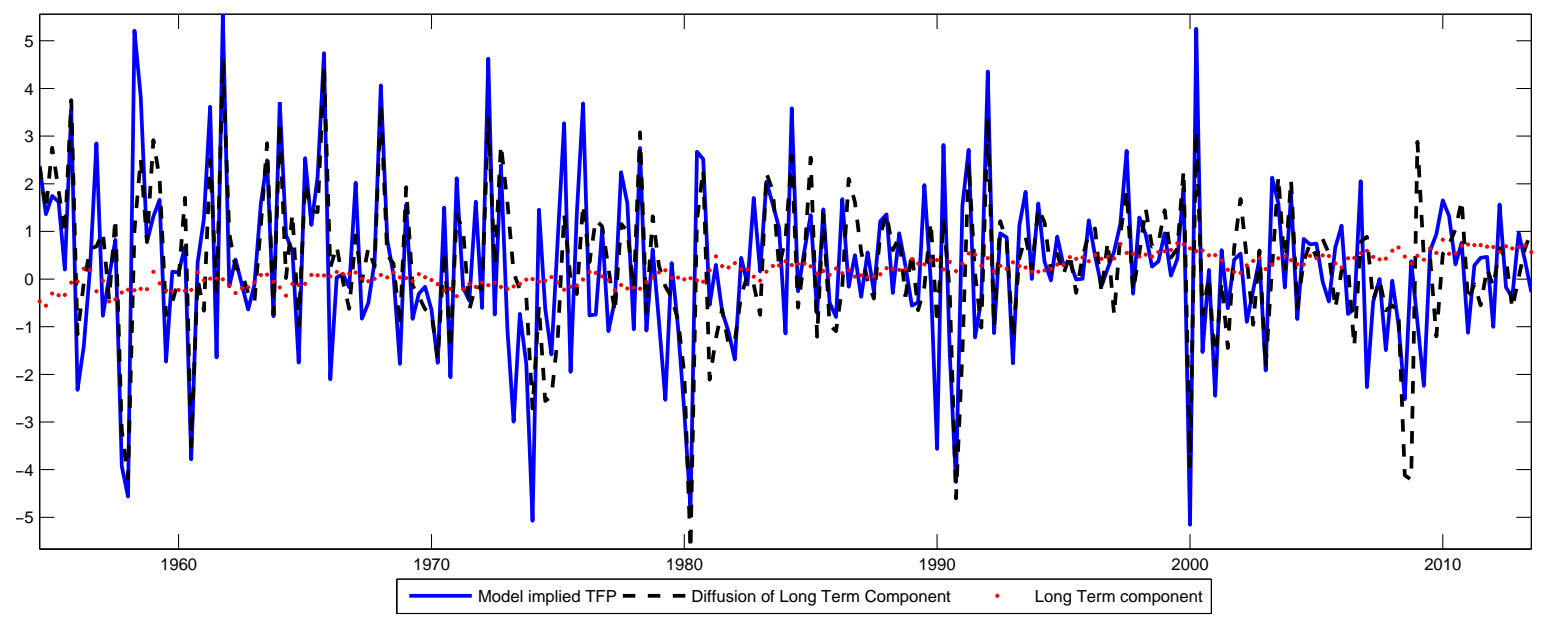

Figure 1 describes the evolution of TFP growth, adopted knowledge, and knowledge.

Figure 2: Shock to the Marginal Efficiency of Investment
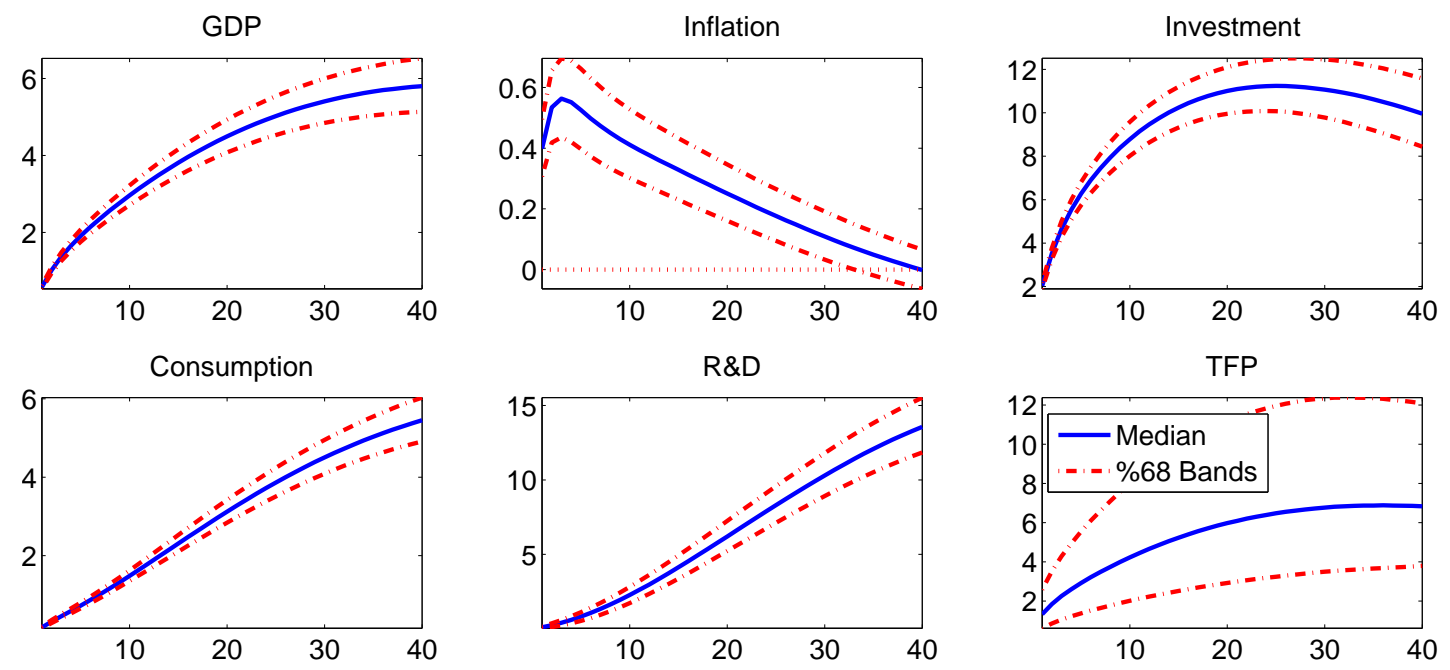

This figure displays impulse response functions for GDP, inflation, investment, consumption, R\&D, and TFP to a positive shock to the marginal efficiency of investment. The solid line corresponds to the median while the dashed lines corresponds to the $68 \%$ error bands. 
Figure 3: Stationary Shock to TFP
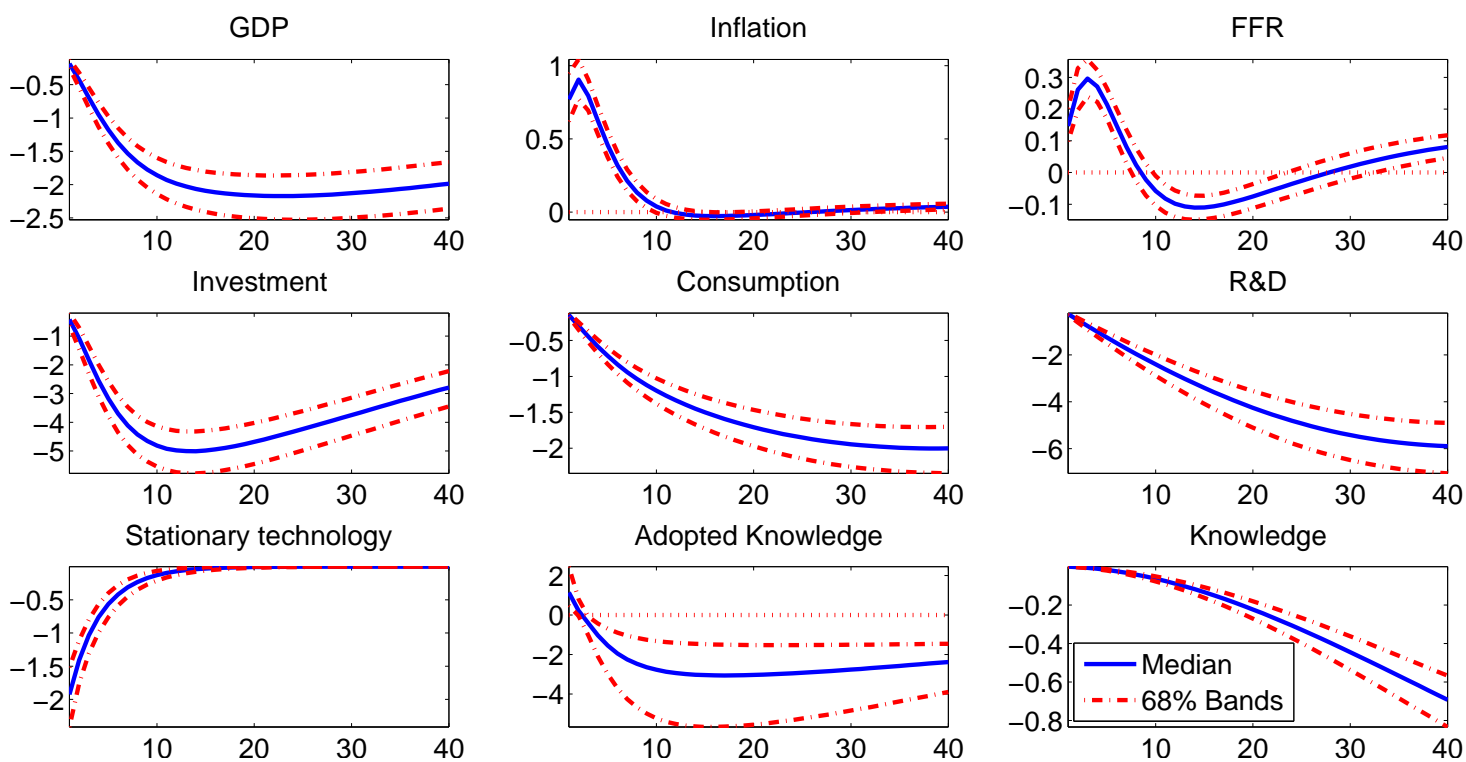

This figure displays impulse response functions for GDP, inflation, investment, consumption, R\&D, and TFP to a negative shock to the stationary component of TFP. The solid line corresponds to the median while the dashed lines corresponds to the $68 \%$ error bands.

Figure 4: Monetary Policy Shock
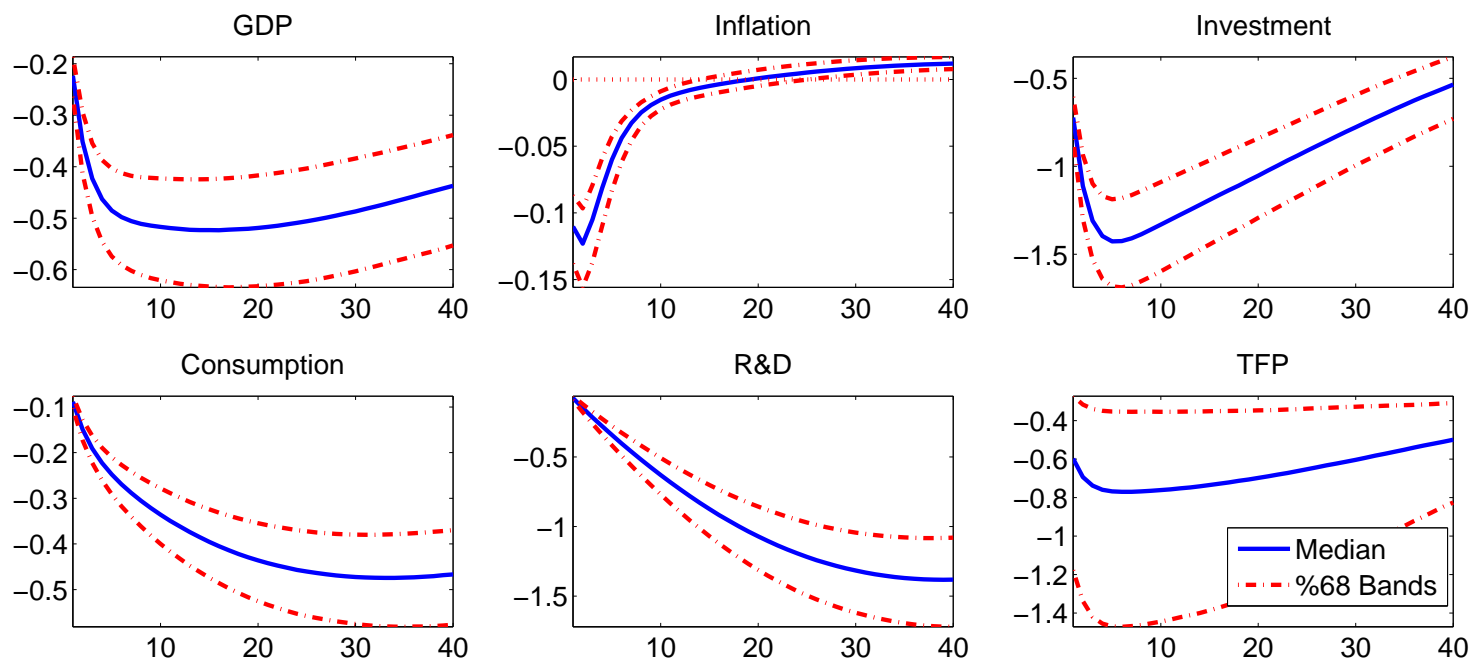

This figure displays impulse response functions for GDP, inflation, investment, consumption, R\&D, and TFP to a contractionary monetary policy shock. The solid line corresponds to the median while the dashed lines corresponds to the $68 \%$ error bands. 
Figure 5: Impact of the Great Recession
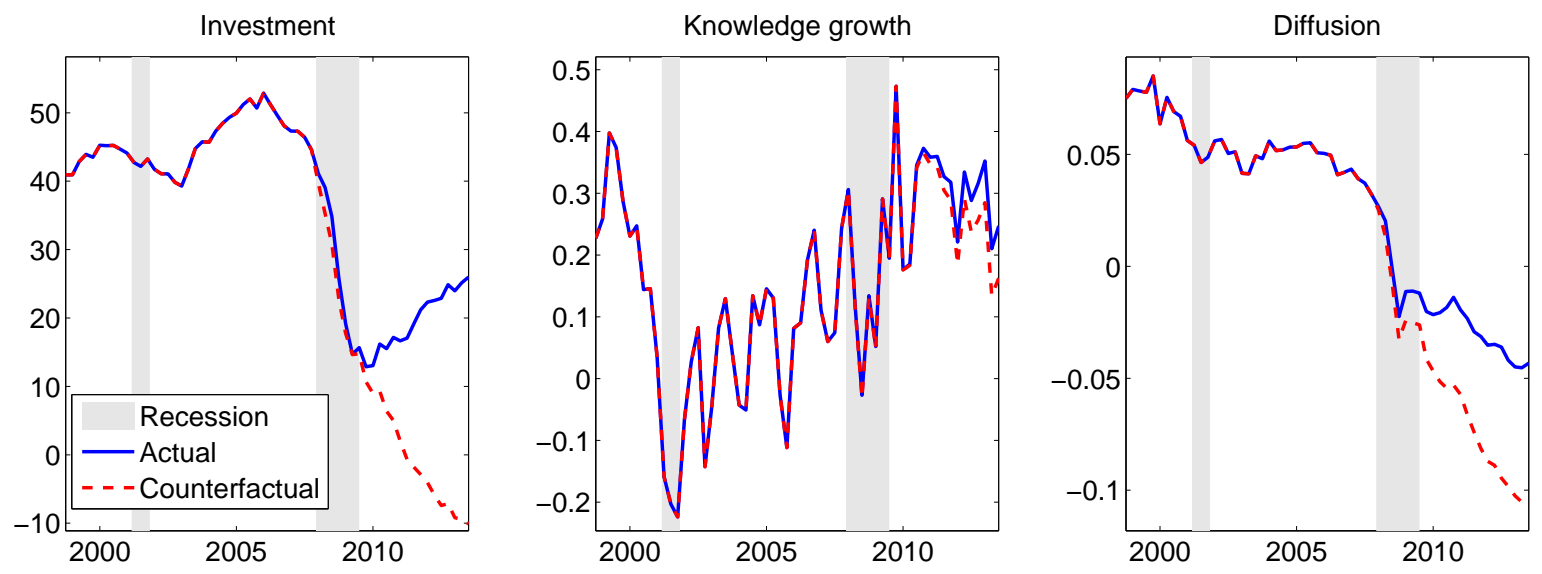

Figure 5 analyzes the Great Recession through the lens of our model. The solid blue line reports smoothed estimates at the posterior mode for Invesment, knowledge growth, and diffusion of technlogy over the past 15 years. The black dashed line corresponds to a counterfactual simulation in which monetary and fiscal shocks are removed starting from the first quarter of 2008. The solid blue line reports smoothed estimates at the posterior mode for Invesment, knowledge growth, and diffusion of technlogy over the past 15 years. The black dashed line corresponds to a counterfactual simulation in which monetary and fiscal shocks are removed starting from the first quarter of 2008.

Figure 6: The Great Inflation
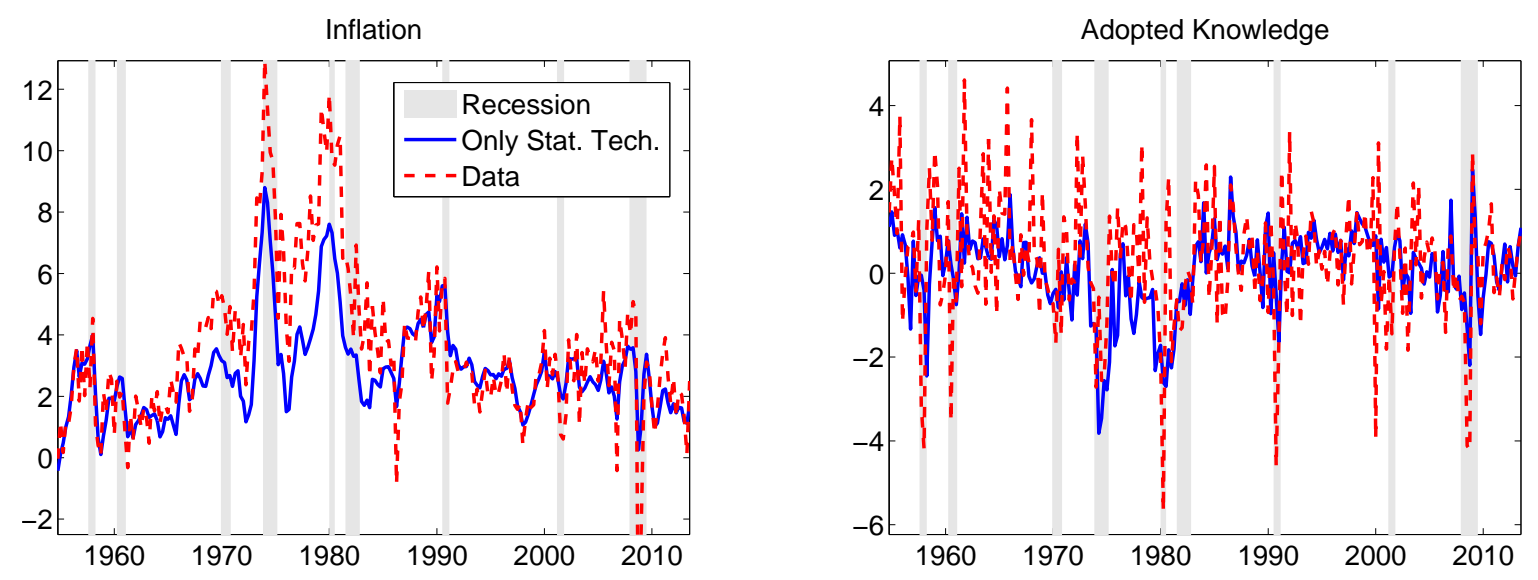

Figure 6 analyzes the Great Recession and the productivity slowdown through the lens of our model. In the left panel, the red dashed line represents actual inflation, while in the right panel, the red dashed line corresponds to the smoothed estimate of the growth rate of adopted knowledge at the posterior model. In both panels, the blue solid line corresponds to a counterfactual simulation in which all shocks, but the stationary technology shock, are set to zero. 